\title{
Cultural norms and behavior regarding vaginal lubrication during sex: Implications for the acceptability of vaginal microbicides for the prevention of HIV/STIs
}

Sarah Braunstein

Janneke van de Wijgert

Follow this and additional works at: https://knowledgecommons.popcouncil.org/departments_sbsr-rh

Part of the Demography, Population, and Ecology Commons, Family, Life Course, and Society

Commons, and the International Public Health Commons

How does access to this work benefit you? Let us know!

\section{Recommended Citation}

Braunstein, Sarah and Janneke van de Wijgert. 2003. "Cultural norms and behavior regarding vaginal lubrication during sex: Implications for the acceptability of vaginal microbicides for the prevention of HIV/ STIs," Robert H. Ebert Program on Critical Issues in Reproductive Health Publication Series. New York: Population Council. 
T HE ROB ER T H. E BER T PROGRAM

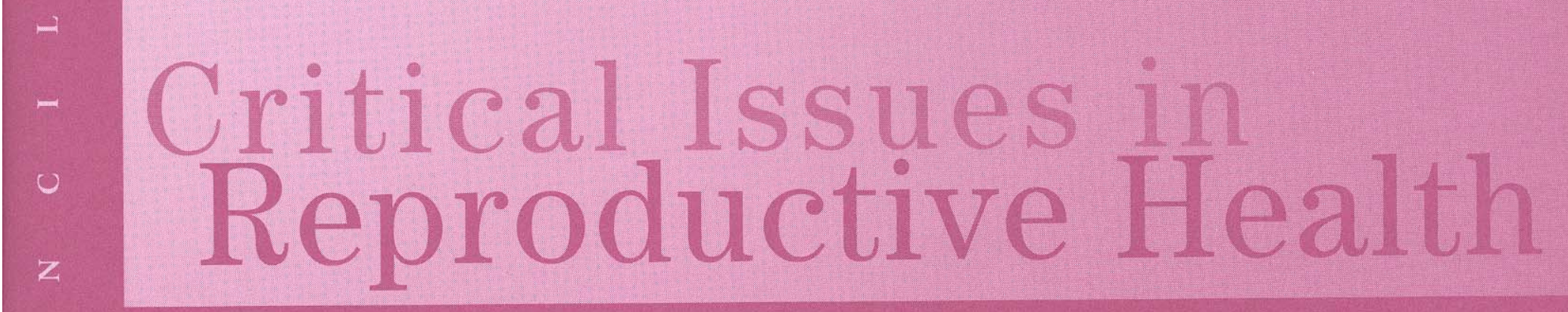

\section{Cultural Norms and Behavior Regarding Vaginal Lubrication During Sex: \\ Implications for the Acceptability of Vaginal Microbicides for the Prevention of HIV/STIs}




\section{Cultural Norms and Behavior Regarding Vaginal Lubrication During Sex: Implications for the Acceptability of Vaginal Microbicides for the Prevention of HIV/STIs}


Cultural Norms and Behavior Regarding Vaginal Lubrication During Sex: Implications for the Acceptability of Vaginal Microbicides for the Prevention of HIV/STIs

Sarah Braunstein, M.P.H.

Janneke van de Wijgert, Ph.D., M.P.H. 
The Population Council is an international, nonprofit, nongovernmental organization that seeks to improve the well-being and reproductive health of current and future generations around the world and to help achieve a humane, equitable, and sustainable balance between people and resources. The Council conducts biomedical, social science, and public health research and helps build research capacities in developing countries.

The Council's Robert H. Ebert Program on Critical Issues in Reproductive Health, named in honor of former Population Council board chair and established in 1988, responds to an awareness that many important reproductive health problems - and the ways women experience them - have been neglected by policymakers, program planners, and practitioners. Reflecting a strong commitment to women's rights and autonomy, and with an overarching focus on improving the quality of services in reproductive health programs, the Ebert Program currently focuses on several areas that merit special attention: managing unwanted pregnancy and preventing the consequences of unsafe abortion, addressing safe motherhood and devising new approaches to postpartum care to meet the health needs of the mother and child, and designing programs that address sexually transmitted infections, including HIV/AIDS, within the larger context of women's reproductive health. The Ebert Program tackles these challenging issues through research, technical assistance, publications, and meetings.

\title{
QP Population Council
}

\author{
The Robert H. Ebert Program \\ on Critical Issues in Reproductive Health \\ Population Council \\ One Dag Hammarskjold Plaza \\ New York, NY 10017 USA \\ 212-339-0500 \\ fax: 212-755-6052 \\ e-mail: pubinfo@popcouncil.org \\ www.popcouncil.org
}

(C) 2003 by The Population Council, Inc.

Cover and text printed on recycled paper in the USA 


\section{Acknowledgments}

We are grateful to Beverly Winikoff, Barbara Friedland, and Heidi Jones of the Robert H. Ebert Program on Critical Issues in Reproductive Health, and to Purnima Mane of the International Programs Division, for reviewing and giving valuable comments on this manuscript. Carole Vance and Kim Hopper at Columbia University also reviewed earlier versions of this report.

We greatly appreciate the support of the William and Flora Hewlett Foundation for the research and this publication. 



\section{Table of Contents}

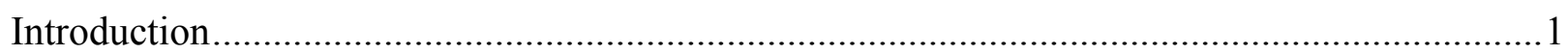

PART ONE: A REVIEW OF THE LITERATURE ..........................................................4

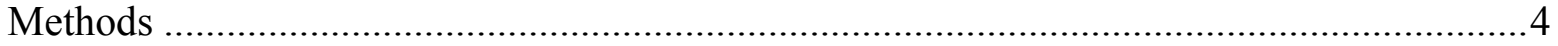

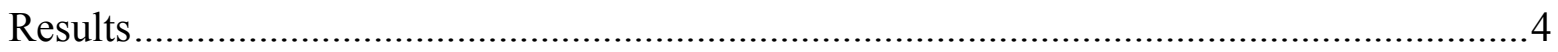

Vaginal lubrication and microbicide and spermicide acceptability ..............................6

Vaginal lubrication and condom acceptability and effectiveness................................

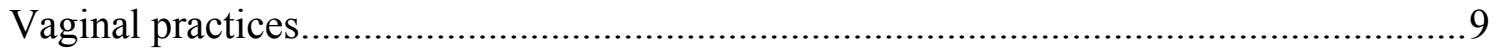

Women's perceptions of vaginal discharge ........................................................... 13

Female sexual (dys)function ............................................................................ 14

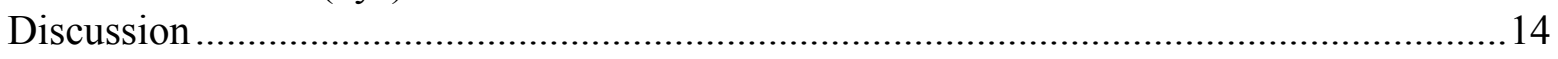

PART TWO: THE PERSPECTIVES OF KEY INFORMANTS ......................................16

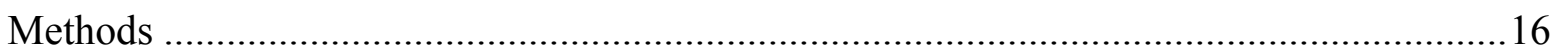

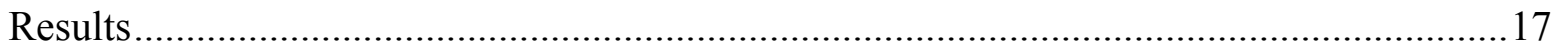

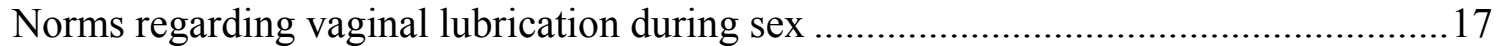

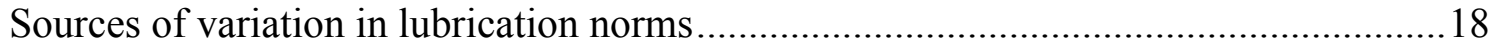

Significance and purpose of lubrication during sex............................................... 19

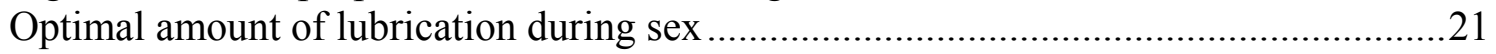

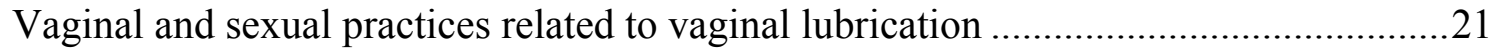

Gender norms and couple communication regarding lubrication during sex .................24

Vaginal lubrication and acceptability of HIV/STI prevention technologies ..................25

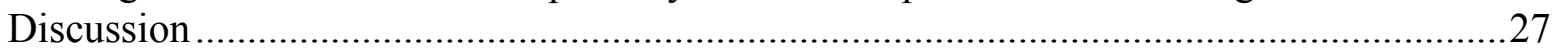

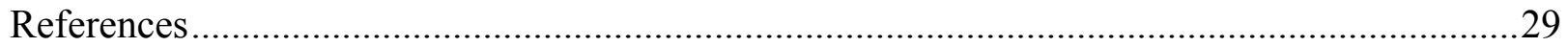

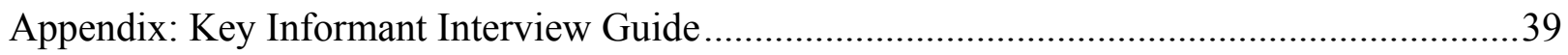





\section{Introduction}

The Joint United Nations Programme on HIV/AIDS (UNAIDS) estimates that 42 million people are currently living with HIV/AIDS (UNAIDS 2002). The proportion of women living with HIV has risen steadily in recent years. In sub-Saharan Africa, where the primary mode of HIV transmission is heterosexual intercourse, more than half of HIV-positive adults are women. The main HIV prevention tools - condoms, reducing the number of sexual partners, mutual monogamy, and treating reproductive tract infections (RTIs) - are not feasible for many women (van de Wijgert and Coggins 2002). Women often have difficulty negotiating male condom use owing to social, cultural, and economic gender inequalities. There is, therefore, an urgent need to extend the range of prevention methods available, particularly those that give women more control.

Vaginal microbicides are being developed and tested to address this need. A microbicide is a product that is applied topically inside the vagina to prevent infection with HIV and, potentially, a number of other bacterial and viral sexually transmitted infections (STIs). Vaginal microbicides may take any of a number of forms, including gels, creams, foams, films, suppositories, or impregnated sponges, and may be contraceptive or not. Microbicides used for vaginal sex are inserted by women, and therefore require only passive acquiescence of men. Microbicides could be used alone or in combination with a physical barrier to provide increased protection or backup in case of barrier failure. More than 50 candidate products are currently being developed; four candidate products, including the Population Council's lead candidate microbicide Carraguard ${ }^{\mathrm{TM}}$, have reached advanced stages of clinical testing.

Because the effectiveness of microbicides will depend on their consistent use, their acceptability to potential users is critical. Acceptability has been defined as follows: "For a product to be acceptable, a potential user must fully understand the potential benefits of using the product, the elements of correct use, its potential side effects, and alternative methods, and be willing and able to consistently apply such knowledge to the use of the technology in everyday life" (Elias and Coggins 2001, p. 164). According to this definition, the acceptability of a product plays a significant role in determining its effectiveness in a given population. A product will be acceptable among a certain group of people to the extent that its features and use dynamics "fit" within their normative or personal frameworks regarding sex and sexuality. However, even without such a niche a product may still be used if individuals or couples decide that the benefit of the product (e.g., protection from HIV infection) is more important than adhering to social or cultural scripts that would otherwise discourage its use.

Microbicide acceptability has been assessed by soliciting individuals' opinions on characteristics or features of a hypothetical vaginal microbicide, often during the preclinical stages of microbicide development; by studying users' acceptance of existing products, such as spermicides, in various formulations; or by assessing the acceptability of a particular experimental vaginal microbicide among clinical trial participants in conjunction with clinical testing of the product (Friedland and McGrory 2001; Bentley et al. 2000; Coggins et al. 2000a, 2000b; Hammett et al. 2000; Darroch and Frost 1999; van de Wijgert et al. 1999; Coggins et al. 1998; Hardy et al. 1998). However, each of these methods has limitations. People do not necessarily know what their attitudes will be toward a new product prior to having actually used 
it; generalizations from other products are not always valid; and clinical trial settings, while a better measure of acceptability than assessments of hypothetical products, rarely approximate "real life." Furthermore, interviewees often report what they think researchers want to hear, resulting in "overestimates" of product acceptability, particularly in the context of clinical trials. Recent reviews of the literature on the acceptability of microbicides have therefore emphasized the importance of taking a broad approach to understanding and measuring acceptability (Mantell et al. in press; Elias and Coggins 2001). In particular, they have underscored the importance of avoiding a narrow focus on individual product characteristics (e.g., color, smell, feel) and examining the influence of the sociocultural context.

According to the Alliance for Microbicide Development (2002), the majority of first-generation candidate microbicides have been formulated as gels that will likely lubricate the vagina during sex. Initially, researchers were concerned that such gels might not be acceptable in countries where "dry sex" is practiced. However, early safety trials in such countries indicated that individuals or couples who practice dry sex were in fact interested in trying a microbicide gel and said that they would use the product in the future if it would protect them from HIV (Bentley et al. 2000; van de Wijgert et al. 1999; Coggins et al. 1998). While this finding is encouraging, there is still much to be learned about cultural factors that influence individuals' preferences and sexual behavior (such as vaginal practices) and are likely to influence microbicide acceptability and use. Further, vaginal practices may render individuals or couples vulnerable to HIV through biological mechanisms or by interfering with STI screening or treatment. Individuals' preferences and practices regarding lubrication during sex ${ }^{2}$ are particularly relevant. An understanding of cultural norms, preferences, and practices regarding lubrication during sex can lead to better understanding of individuals' and groups' vulnerability to HIV, and can influence how microbicides are introduced and eventually used.

This paper comprises two parts. In the first part, we present the results of an extensive review of the literature pertaining to the relationship between vaginal lubrication and the acceptability of microbicides, spermicides, and male and female condoms. While hardly any literature exists on preferences and practices regarding vaginal lubrication during sex per se, we found relevant information in the following areas: vaginal practices (i.e. vaginal drying, tightening, or cleansing, including menstrual hygiene practices); women's perceptions of vaginal discharge and health-seeking behavior for perceived "abnormal" discharge; and clinical definitions of women's sexual function and dysfunction. This review of the literature highlights the need for research that better elucidates norms, preferences, and practices regarding lubrication during sex within and across countries. ${ }^{3}$

In the second part, we present the results of the first phase of a qualitative study on lubrication

\footnotetext{
${ }^{1}$ To achieve "dry sex," women remove vaginal secretions prior to sex.

${ }^{2}$ In this report, the term "lubrication during sex" refers broadly to the presence of lubrication, vaginal fluid, or "wetness" in the vagina during sexual intercourse; it is meant to include vaginal lubrication produced naturally by the body as well as commercial lubricant products. References to preferences regarding lubrication during sex refer to individuals' and couples' ideas concerning the presence, type, and amount of vaginal lubrication they desire during sex; practices regarding lubrication during sex refer to actions that individuals - whether alone or within a partnership - take to alter or maintain vaginal lubrication.

${ }^{3}$ This report focuses on sex and relationships between women and men as the majority of STIs, including HIV, in developing countries are transmitted through heterosexual sex.
} 
during sex. We interviewed 13 key informants in the fields of women's sexual and reproductive health, public health, and HIV prevention from nine countries in Africa, Asia, Latin America, and North America. Informants' professional perspectives on norms, preferences, and practices regarding lubrication during sex in the countries in which they work were solicited. Interview data highlight that diverse personal and cultural factors shape preferences and practices and may ultimately affect the acceptability of microbicides. 


\section{PART ONE: A REVIEW OF THE LITERATURE}

\section{Methods}

We reviewed the literature using electronic searches, primarily the PubMed, MEDLINE, POPLINE, OVID, and Anthropological Index Online search engines, to identify articles published between 1980 and October 2002. This review focuses on articles published from the early 1990s to the present. The search drew from literature in a range of disciplines, including general and applied public health, HIV/STI prevention, and the social sciences. Initial searches helped to build a framework for the review; a primary search for articles on vaginal lubrication and sex yielded very little. Subsequent literature searches were conducted using such keywords as "microbicide acceptability and lubrication," "vaginal practices," "dry sex," "vaginal practices and HIV or STIs," "cultural sexual practices," "hygiene and sex," "douching," and "vaginal discharge."

In total, 114 articles were included, 90 articles published between 1995 and October 2002 and 24 published prior to 1995. Articles were selected according to several criteria. Articles were excluded if they only cursorily discussed the topic of lubrication during sex, if they were published in a non-peer-reviewed publication (e.g., a newsletter), or if they were published in the 1980 s or early 1990 s and similar information had been published more recently in a peerreviewed journal. Fifteen articles published between the early 1990s and the present were excluded from the final list for these reasons. The majority of articles were included if they were relevant to the topic or if they represented the only published literature pertaining to vaginal lubrication in a certain country or among a particular group of people.

\section{Results}

A comprehensive review of the literature on vaginal lubrication and lubrication during sex yielded a limited number of articles whose primary focus was lubrication preferences and practices. In particular, only a few articles on the acceptability of microbicides or other contraceptive and HIV/STI prevention technologies explicitly inquired into participants' understanding of and preferences for lubrication during sex. Literature in other areas of reproductive health, sexual health, and sexuality was therefore also reviewed for content related to vaginal lubrication and lubrication during sex. An examination of the literature reviewed in each of these areas follows.

A visual schema representing the areas of literature reviewed, and their connection to the central research questions, is presented in Figure 1. 


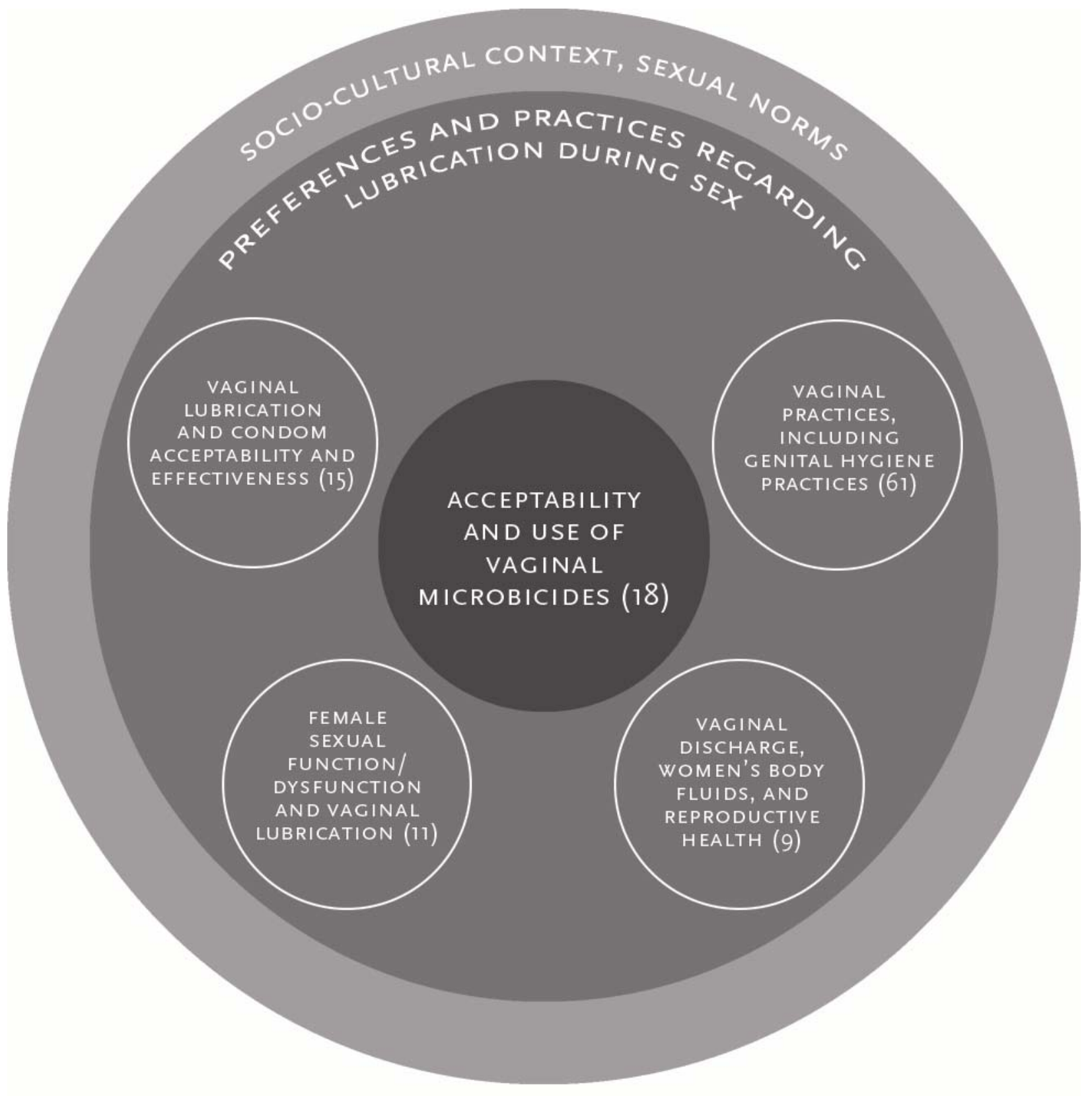

Figure 1. Areas of literature reviewed (numbers of articles reviewed in each area shown in parentheses). 


\section{Vaginal lubrication and microbicide and spermicide acceptability}

Studies in a number of countries have found that the degree of lubrication-most frequently described as "wetness" or "messiness" - is an important determinant of acceptability of microbicides and spermicides. Most of these studies have assessed the acceptability of a variety of existing over-the-counter spermicides or sexual lubricants in different formulations, including films, gels, suppositories, foaming tablets, and impregnated sponges.

Steiner et al. (1995) surveyed women's preferences for spermicidal film and foaming tablets in the Dominican Republic, Kenya, and Mexico. The vast majority of women surveyed preferred film over foaming tablets; the most frequently cited reason being that foaming tablets were messy or too wet. In a study conducted among women from the general population in Côte d'Ivoire $(\mathrm{N}=31)$, Thailand ( $\mathrm{N}=61)$, the United States $(\mathrm{N}=31)$, and Zimbabwe $(\mathrm{N}=22)$, participants from most sites expressed a preference for film and gel over the suppository, largely because of perceived excessive lubrication and messiness associated with suppository use, and perceptions that the film made the vagina feel "tight" and "fit" (Coggins et al. 1998). Some women preferred gel over film because they found the gel easier to insert and liked the fact that it was active immediately after insertion. However, others thought that the gel was too messy and compensated for this by decreasing the volume of gel they applied. In a consumer preference study of a hypothetical vaginal product among 635 adolescent and adult women from varied socioeconomic backgrounds in São Paolo, Brazil, degree of lubrication was also a significant determinant of acceptability (Hardy et al. 1998). Most participants felt that excessive volume, defined in the study as "messiness," would serve as a barrier to product acceptability; however, messiness of the product became less significant if the product provided dual protection against STIs and pregnancy, particularly among the adult women in the sample. In a study of drug-using women and female sex partners of male drug users in the continental United States and Puerto Rico, the most undesirable aspects of lubricant formulations tested was their perceived messiness (Hammett et al. 2000). Some women worried that excessive lubrication might be interpreted by their male partners as evidence of infection, infidelity, or inadequate hygiene, and reported reducing the dose of the product by cutting the suppository in half or only partially filling the applicator. Women had diverse responses to the lubricant products being tested. Some women, particularly those who reported vaginal dryness, said that the products made sex more pleasurable. The authors posited that women's responses to the products were due to variation in preferences regarding lubrication as well as to differences in the women's natural lubrication.

Focus group discussions with men in Mexico $(\mathrm{N}=41)$, the United States $(\mathrm{N}=30)$, and Zimbabwe $(\mathrm{N}=35)$ about a hypothetical microbicide found that the degree of lubrication would significantly affect men's willingness to use such a product during sex with a female partner (Coggins et al. 2000b; van de Wijgert et al. 1999). In particular, men from Zimbabwe felt that a product that increased lubrication during sex would not be acceptable, given the popularity of dry sex and the association of vaginal lubrication with promiscuity and disease. Men from the United States said they might be less willing to use a product that they felt was too messy or that could easily be detected during sex. Ramjee et al. (2001) interviewed 243 South African men for their opinions on a potential vaginal microbicide. In general, the men reported that they preferred small amounts of lubrication during sex, indicating that the volume of a microbicide will likely be key to its acceptability. 
In contrast, studies in Uganda and Zambia found that female and male participants most preferred products they believed increased sexual pleasure primarily by enhancing lubrication during sex (Green et al. 2001; Hira et al. 1995; see also Pool et al. 2000a, 2000b). Even in this context, however, a number of female and male participants in Zambia reported that the least favorable features of foam, suppositories, and tablets were excessive lubrication, messiness, or increased vaginal discharge; of the three formulations, participants found foam to be least acceptable.

Acceptability assessments in clinical trials of microbicides have generated similar findings regarding the lubricating properties of test products. As a result of acceptability assessments during a multi-site Phase 1 study of the candidate microbicide PC-503, the Population Council reduced the gel volume from 5 to $4 \mathrm{ml}$ for subsequent formulations tested (Coggins et al. 2000a). Acceptability assessments in a multi-site Phase 1 study of the candidate microbicide BufferGel $^{\mathrm{TM}}$ showed that individuals in countries where dry sex is practiced (such as Zimbabwe) may find a certain level of lubrication acceptable, particularly if the product provides protection from HIV (Bentley et al. 2000). Participants in both studies also noted that the study gel made their vaginas feel clean and fresh - they clearly differentiated added lubrication from the study products from natural vaginal lubrication or discharge as a result of vaginal infections.

\section{Vaginal lubrication and condom acceptability and effectiveness}

The relationship between vaginal lubrication and the acceptability and effectiveness of male and female condoms has been studied extensively. Some of this literature focuses on amount or type of lubrication as a risk factor for male condom breakage or slippage. One study explored reasons for condom breakage and slippage among a sample of 540 male and female family planning clients in New Zealand (Sparrow and Lavill 1994). The researchers found no association between "adequacy of [vaginal] lubrication" 4 and reported condom failure. Further, the researchers did not find an association between the use of artificial lubricants during sex and condom breakage or slippage. However, they did find that individuals who experienced the highest numbers of breaks and slips reported vaginal dryness or inadequate lubrication during sex. A study on the impact of specific behaviors and user characteristics on condom failure among men in the Dominican Republic, Mexico, and the Philippines also found that dry or nonlubricated sex may lead to increased frequency of condom breakage or slippage (Spruyt et al. 1998). Furthermore, in a study of reasons for condom failure among 525 female students presenting for emergency contraception at student health service centers and 481 controls, the use of water-based lubricants was strongly associated with lower rates of condom slippage (Gabbay and Gibbs 1996). In contrast, a study on the impact of the behavior of 268 American couples on condom efficacy found that the use of artificial lubricants increased the rates of condom slippage (Steiner et al. 1994). In a study of 194 Australian men who used a total of 3,607 condoms, Smith et al. (1998) found that the use of lubricants more than doubled the risk of

\footnotetext{
4 "Adequacy of natural lubrication" was measured as time spent on foreplay. The researchers report that foreplay lasted longer than 5 minutes in $80.3 \%$ of the 3,754 sex acts they assessed, but aren't explicit as to whether or not they consider this to be adequate. This definition is problematic for several reasons: first, the duration of foreplay may not correlate with lubrication, particularly in "dry sex" areas; second, women may not control foreplay; and third, women and men may evaluate lubrication differently.
} 
condom slippage (but not breakage) for vaginal sex and hypothesized that users' fears of condom slippage could act as a deterrent to their use.

Rojanapithayakorn and Goedken (1995) studied the impact of lubrication on the effectiveness and acceptability of male condoms among sex workers in Thailand. In general, participants were interested in using condoms, but side effects such as breakage during sex, discomfort and pain, and negative effects on clients' sexual enjoyment interfered with consistent use. When participants were given water-based lubricants to use in conjunction with condoms, side effects were reduced and acceptance of condoms increased.

The impact of vaginal practices on male condom use has also been explored. Civic and Wilson (1996) discussed the effect of such practices on condom use with female HIV/AIDS peer educators in Zimbabwe using focus group discussions. In general, sex workers reported that engaging in dry sex negatively affects condom use: women who regularly dried their vaginas prior to sex reported that condoms frequently broke during sex and cited concerns that condom use would interfere with the effectiveness of drying agents. ${ }^{5}$ Karim et al. (1995) found that men may be unwilling to use condoms in areas where dry sex is practiced, such as South Africa, because they present an obstacle to assessing their female partners' vaginal wetness prior to or during sex. In a qualitative study by Ray et al. (1996), Zimbabwean men expressed anxiety around condom use because they were not able to discern whether lubrication came from the condom or their female partner.

Several studies have assessed the relationship of preferences regarding lubrication with the acceptability of the female condom. In general, studies have found that excessive lubrication is one of the most common complaints about the female condom (Hatzell and Feldblum 2001). In a study of the acceptability of the female condom among sex workers in Zimbabwe, most women viewed the added lubrication from the condom favorably, although some complained about excessive lubrication (Ray et al. 1995). The researchers attributed the mixed acceptability of the female condom to the high value placed on dry sex in Zimbabwe. In a survey of family planning providers' attitudes regarding and experiences with the female condom, South African providers expressed concern that women's discomfort with touching their vaginas and male preferences for dry sex would serve as barriers to acceptability of the method (Mantell et al. 2001). In a prospective study of the acceptability of the female condom, Jivasak-Apimas et al. (2001) reported that $56 \%$ of the 148 Thai sex workers in their sample complained of excessive lubrication after eight weeks of condom use. Despite this complaint, the majority of participants said they would use the method in the future, particularly if it provided protection against $\mathrm{HIV} / \mathrm{STIs.}$

\footnotetext{
${ }^{5}$ Participants in the study by Civic and Wilson (1996) did, however, report that they liked the lubrication on prelubricated condoms and that they sometimes used lubricants during sex, which suggests that some lubrication is desired.
} 
Studies have also reported that noise produced during use of the female condom may be a potential barrier to use. In most of these articles, however, the type and amount of reported noise is not well defined, and some researchers suggest, but do not elaborate on, a relationship between noise and amount of lubrication. For instance, Witte et al. (1999) report that roughly a third of the women they surveyed who engage in street sex in New York City felt that the female condom was "noisy or squeaky," but also that it was "sufficiently lubricated." In a study of sex workers in Côte d'Ivoire, about half of the participants reported noise during sex, and several reported that they felt the condom was either overly or inadequately lubricated (Deniaud and Fampou-Toundji 1999). Séhonou et al. (2002) report that $35 \%$ of the family planning clients they surveyed in the Central African Republic described a noise during use of the female condom, but the researchers do not explain the cause of the noise. In an acceptability study of the female condom and a latex prototype among 135 couples in the United States, only a few couples reported experiencing noise during use, and the majority reported neutral feelings regarding the amount and feel of the lubricant (Latka et al. 2001). Lastly, Mantell et al. (in press) asked providers to use female condoms themselves; providers cited excessive lubrication (defined as "messiness") and noise during sex as negative aspects of the method.

\section{Vaginal practices}

Vaginal practices — and ideas about vaginal lubrication during sex — will likely have an effect on the acceptability and use of microbicides. Broadly, vaginal practices involve the insertion or external use of a substance or material to affect sexual pleasure or satisfaction, hygiene, fertility, or reproductive health (Brown and Brown 2000). Traditional vaginal practices are usually taught to young women by their older female relatives, female peers, or other women in the community, and represent, to some extent, a culture's norms and ideologies about the body. For example, if people believe sex should be "dry," they may use products that dry the vagina prior to sex. Further, although women typically initiate vaginal practices without the involvement of their male partners, engaging in such practices depends heavily on gender roles, interpersonal dynamics, and couple communication. As such, engaging in vaginal practices may or may not align with women's own sexual desires. Cultural or religious values and ideas that describe women's bodies as contaminated or impure influence women's perceptions of their own bodies and sexuality, men's perceptions of women's bodies and sexuality, and individuals' and couples' sexual behavior (e.g., Bang and Bang 1994; Snowden and Christian 1983). Societal or personal perceptions of vaginal lubrication, discharge, or menstrual blood as "dirty" or "unclean" might compel women to engage in practices to alter or remove vaginal fluids prior to sex in order to demonstrate good personal hygiene and adherence to sociocultural norms (Vermund et al. 2001; Ray et al. 1996; Pitts et al. 1994). A review of the literature on vaginal practices demonstrates that such practices are one mechanism through which dominant sociocultural and sexual idealsrelating to gender, sexuality, the body, and notions of "health" and "illness" - are reinforced.

Vaginal practices have been reported in sub-Saharan, central, east, and west Africa, and in the Dominican Republic, Haiti, Indonesia, Qatar, Thailand, and the United States (Koblin et al. 2002; Reed et al. 2001; van de Wijgert et al. 2001; Brown and Brown 2000; Halperin 1999, 2000; Foxman et al. 1998; Kun 1998; Grésenguet et al. 1997; Quigley et al. 1997; Ray et al. 1996; Dallabetta et al. 1995; Karim et al. 1995; Orubuloye et al. 1995; Awusabo-Asare et al. 1993; Runganga et al. 1992; Roddy and Feldblum 1991; Hira et al. 1990; Mann et al. 1988). 
They include wiping the vagina or inserting substances into the vagina to dry it by removing vaginal fluids; inserting herbal or nonherbal preparations to constrict or tighten the vaginal walls; or inserting commercial or noncommercial substances to douche or cleanse the vagina and genital area. Substances used may include stones, leaves, herbs, powders, water with or without soap, dry cloth, pharmaceutical products (such as antiseptic liquid soaps and commercial douches), and tissue or toilet paper.

Although limited data exist on the prevalence of vaginal practices, research suggests that they are common among some groups or cultures. A recent study found that vaginal cleansing, drying, or tightening was practiced by $13 \%$ of women in Thailand, $67 \%$ in Uganda, and $60 \%$ in Zimbabwe (van de Wijgert et al. 2002). The most common practice was vaginal cleansing with water, or water and soap, using a finger. A study in South Africa found that women in Gugulethu (near Cape Town) and Ga-Rankuwa (near Pretoria) inserted vaginal products for the following reasons: cleansing (19\% in Gugulethu, $52 \%$ in Ga-Rankuwa), drying and/or tightening (8\%, $5 \%)$, treatment of vaginal infections $(35 \%, 22 \%)$, and menstrual hygiene $(27 \%, 21 \%)$ (Jones et al. 2002). Studies suggest that douching is common among women and adolescents in the general population in the United States, with estimates ranging from $15.5 \%$ to $33-69 \%{ }^{6}$ (Foch et al. 2001; Merchant et al. 1999). Young African-American women are purportedly more likely to douche than middle-aged, older, or white American women, and it has been suggested that douching is associated with lower socioeconomic status, low education, and greater risk for STIs (Funkhouser et al. 2002; Koblin et al. 2002; Vermund et al. 2001; Merchant et al. 1999; Kendrick et al. 1997; Rosenberg et al. 1991).

Women cite numerous reasons for engaging in vaginal practices. Generally, they believe that such practices promote cleanliness, fertility, and good health, and enhance their male partner's sexual arousal and pleasure (van de Wijgert et al. 2001; Brown and Brown 2000; Beksinska et al. 1999; Pitts et al. 1994). Women cite less frequently their own sexual pleasure or satisfaction as a reason for engaging in vaginal practices.

Women commonly perform vaginal practices to achieve genital hygiene. In the literature these practices are referred to as douching or genital cleansing. Women douche for a variety of reasons, including to remove menstrual blood, vaginal discharge, undesirable odors, or semen after sexual intercourse; to prevent or treat sexually transmitted or vaginal infections or pregnancy; and to enhance sexual pleasure or satisfaction by creating a feeling of cleanliness and "readiness" for sex (Oh et al. 2002; van de Wijgert et al. 2001; Lichtenstein and Nansel 2000; Grésenguet et al. 1997; Dallabetta et al. 1995; Orubuloye et al. 1995; Rosenberg et al. 1991). In addition to

\footnotetext{
${ }^{6}$ This extremely wide range results from prevalence studies using different methodologies and study populations. Foch et al. (2001) derive their estimate of 33-69\% from several other studies on the prevalence of douching; these studies collected data in a variety of ways, including surveying inner city adolescent family planning clients (Chacko et al. 1989); administering questionnaires to 618 women ages 18-50 presenting at gynecological clinics (Rosenberg et al. 1991); and personal interviews with a nationally representative sample of 8,450 sexually active women of reproductive age (Aral et al. 1992). Merchant et al. (1999) derive their figure of $15.5 \%$ from the 1995 National Survey of Family Growth. Each of these studies employed the same definition of "douching"- the use of a commercial douche product to cleanse the vagina.
} 
cleansing, cold water is sometimes used to tighten the vagina and enhance friction during sex (van de Wijgert et al. 2001).

In some countries, women may remove vaginal secretions to dry the vagina in preparation for sex, or use substances to tighten or warm the vagina (Halperin 2000; Kun 1998; Sandala et al. 1995). Pitts et al. (1994, p. 98) explain: "The purposes of the herbs and/or agents are clear. They are meant to make the vagina small by drawing the moisture out of it, which also makes it dry. A lubricated vagina is not considered desirable in [Zimbabwe]; men prefer small, tight, and dry vaginas." Women report that a dry, tight vagina ensures their male partners' sexual satisfaction by enhancing friction and heat in the vagina during sex. Men may interpret the presence of vaginal lubrication during sex as an indication of a woman's infidelity - as a sign that she has had recent sexual relations with another man (Ray et al. 1996). Women whose partners express such concerns may insert substances to remove vaginal secretions prior to sex to ensure their partners' sexual satisfaction and the security of the relationship.

Another reason cited by women for engaging in vaginal practices is the enhancement or preservation of fertility. For example, the practice of dry sex is promoted in Zimbabwe, in part, by a widespread belief that fertilization can only take place in a clean, dry environment (Runganga and Kasule 1995). Women also may perform vaginal practices or undergo surgery to restore and tighten the vaginal walls and muscles after childbirth (Braun and Kitzinger 2001; Brown and Brown 2000; Runganga et al. 1992). Sex workers may engage in vaginal practices to clean the vagina between clients in order to remove "evidence" of previous clients; to ensure the sexual satisfaction of clients; and to prevent or treat infection (Fonck et al. 2001; Reed et al. 2001; Kilmarx et al. 1998; Karim et al. 1995; Morar and Karim 1998). Sex workers' increased risk for STIs, their greater perception of risk, and the greater likelihood that they will have vaginal symptoms are important reasons for the high prevalence of vaginal practices in this group.

The literature contains references to potential consequences for women who fail to properly prepare themselves for sex through vaginal or other practices, ranging from relationship problems to violence or abandonment for women in the general population, and from economic repercussions to physical or sexual violence for female sex workers. Orubuloye et al. (1995) reported that Nigerian women who fail to clean their vaginas prior to sex may be reprimanded by their male partners, forced to clean themselves, or deprived of sex. In areas where dry sex is practiced, women who fail to remove vaginal secretions prior to sex often face accusations of infidelity. Pitts et al. (1994) reported that some female university students in Zimbabwe believed that if men were to discover that their female partners engaged in vaginal drying or tightening practices, the woman could face violence or abandonment. ${ }^{7}$ This finding alludes to an interesting conflict in that women are expected to be naturally and regularly ready for sex but are not supposed to actively prepare themselves for sex. Notwithstanding the evidence cited from these two studies, there is little empirical evidence in the literature on the prevalence of violence or psychological abuse against women for these reasons.

\footnotetext{
${ }^{7}$ Unfortunately, we are unable to get a sense of the potential magnitude of the problem from this study because the authors do not cite the number of female participants who reported this belief.
} 
Researchers have suggested a link between vaginal practices and increased risk of infection with HIV and other STIs. Three mechanisms for the link have been proposed: (1) vaginal practices may dry and irritate the vaginal and cervical mucosa, causing inflammation (Fonck et al. 2001; Brown and Brown 2000; van de Wijgert et al. 2000a; Brown et al. 1993; Hunter 1993; Irwin et al. 1993; Brown et al. 1992); (2) vaginal practices may disturb the normal vaginal flora and eliminate lactobacilli that form a natural barrier against colonization by STI pathogens and transmission of HIV (van de Wijgert et al. 2000b, 2002; Martin et al. 1999; Taha et al. 1998; Sewankambo et al. 1997; Zhang et al. 1997; Cohen et al. 1995; Klebanoff and Coombs 1991); and (3) vaginal practices may interfere with the acceptability and efficacy of barrier methods for HIV/STI prevention (Civic and Wilson 1996; Dallabetta et al. 1995; Runganga and Kasule 1995).

Data on the association between vaginal practices and HIV are inconclusive, primarily because of the lack of prospective studies designed to study this association. Studies that link vaginal practices to abnormal vaginal flora and bacterial vaginosis and other studies that link bacterial vaginosis to HIV provide some indirect evidence of the potential harmful effects of vaginal practices on acquisition of HIV (see, for example, Fonck et al. 2001; Pavlova and Tao 2000; Rajamanoharan et al. 1999; Zhang et al. 1997; Cohen et al. 1995; Onderdonk et al. 1992). Crosssectional studies also provide some preliminary — albeit conflicting —evidence. In a study of HIV prevalence and risk factors among pregnant women in Harare, Zimbabwe, Mbizvo et al. (1996) found that women who engaged in vaginal practices were more likely to be HIV-positive. However, Sandala et al. (1995) found no association between vaginal drying practices and increased risk for HIV infection among women in Lusaka, Zambia. Similarly, Orubuloye et al. (1995) found no association between traditional cleaning and drying practices and HIV among Nigerian women, and Nzila et al. (1991) found that insertion of commercial or traditional substances by sex workers in Kinshasa, Zaire was not associated with HIV infection. Prospective studies designed to evaluate the association between vaginal practices and HIV acquisition are ongoing.

Data on the effects of vaginal practices on other STIs are also inconclusive. Grésenguet et al. (1997) found that douching with commercial preparations was associated with greater condom use and lower risk for STIs among women in Central Africa. However, Joesoef et al. (1996) found that douching with commercial agents or water and soap was associated with a higher prevalence of STIs among pregnant women in Indonesia, depending on the timing of douching and the product used; douching before sex and douching with water and soap, betel leaf, or a commercial product correlated with a higher prevalence of infections. Further, Koblin et al. (2002) found a negative correlation between the use of spermicides and recent douching and a positive association between the number of male partners and douching among a cohort of US women at risk for HIV/STIs. A major limitation of these studies is that their cross-sectional design prevents us from knowing whether douching has contributed to infection, or whether participants who had vaginal infections douched in response to symptoms. 
Additional insight into norms regarding vaginal lubrication can be gleaned from a review of the relevant public health and anthropological literature on women's perceptions of vaginal discharge. Several studies have investigated women's interpretations of "normal" versus "abnormal" vaginal discharge, and when and why they decide to self-treat or seek medical treatment (Gorbach et al. 1997; Bro 1993; O'Toole Erwin 1993). For instance, in a study of perceptions of vaginal discharge among Danish women, participants' understanding of normal vaginal lubrication varied greatly (Bro 1993). Although many of the women were bothered by typical amounts of vaginal secretion, most accepted such amounts as normal. These women sought medical attention only when they experienced what they considered a significant increase in this typical amount. Other women who were concerned by the amount of their typical discharge sought medical treatment without experiencing any change in the amount or type of discharge. In a similar study conducted in Vietnam, women sought medical treatment for vaginal discharge when it appeared different (in color, odor, texture, or amount) from their normal discharge, regardless of how the normal discharge appeared or was interpreted (Gorbach et al. 1997). In general, study participants shared beliefs about normal vaginal and sexual health. However, participants' views varied in terms of their awareness of symptoms, perceptions of the seriousness of symptoms, experiences of illness, and opinions on when treatment should be sought for symptoms, or whether and when they should self-treat.

There is a significant body of literature on "white discharge" or leukorrhea among women in India (Bhatti and Fikree 2002; Trollope-Kumar 2001; Patel and Oomman 1999; Winkvist and Akhtar 1997; Bang and Bang 1994; Chaturvedi et al. 1993; Nichter 1989). In a qualitative study of women in rural India, participants associated white discharge with a host of sexual and environmental causes and behaviors, including sexual promiscuity and infidelity, generalized physical or psychological "weakness," elevated body heat, excessive sexual desire, and other lifestyle habits and "exposures" (Bang and Bang 1994). Women ascribed white discharge to a mix of illness-related and social/sexual-related events or behaviors, and reported cleansing their genitals prior to sex to protect themselves and their male partners from the negative health effects of white discharge. In a study of low-income, urban women in Pakistan, white discharge was a commonly reported health problem that women viewed as an expected experience of womanhood. As a result, medical treatment for the condition was sought infrequently (Winkvist and Akhtar 1997). Among participants in an ethnographic study of health-seeking behavior among women with RTIs in Karachi, Pakistan, vaginal discharge was a common complaint (Bhatti and Fikree 2002). Women reported that discharge interferes with their physical health (causing "weakness") as well as with religious obligations, work, social activities, and sex. The researchers attributed women's negative perceptions of vaginal discharge to misinformation from allopathic doctors regarding the causes of vaginal discharge; health providers' lack of attention to the mental health or social ramifications of RTIs; and stigmatization resulting from strong cultural and religious norms regarding cleanliness. 


\section{Female sexual (dys)function}

Literature on female sexual (dys)function, generated primarily by researchers and clinicians from the United States, directly addresses the issue of vaginal lubrication in the context of sex. To be sure, the American clinical sex research community's understanding of the significance of vaginal lubrication to women's sexual and psychological health, function, and pleasure drives the literature on this topic. However, it is plausible that women's and men's own ideas about sex, sexual function, and pleasure may be influenced by a similar understanding.

Diminished vaginal lubrication or difficulty lubricating during sex is a principal component of sexual arousal disorder, which is one of the four major categories in the clinical definition of female sexual dysfunction. Inadequate vaginal lubrication is also associated with sexual pain disorders such as dyspareunia or vaginismus (Berman and Bassuk 2002; Berman and Goldstein 2001; Berman et al. 2000; Goldstein 2000; Berman et al. 1999; Laumann et al. 1999; Leiblum 1998; Kutteh et al. 1996). According to Anastasiadis et al. (2002), a national survey in the United States indicated that approximately $20 \%{ }^{8}$ of women report difficulty lubricating during arousal or sex. Some of the literature addressing the role of vaginal lubrication in sexual dysfunction concerns changes in women's sexual functioning as a result of menopause and aging, including decreased libido or vaginal lubrication (Gelfand 2000; McMaster et al. 1997).

Until recently, the clinical sex research community discounted the study of women's subjective experiences of desire, pleasure, and satisfaction. The field is increasingly committed to expanding traditional notions of female sexual function to include subjective measures of sexual function, desire, and experience, and to developing new models that expand the previously narrow focus on physiological markers of sexual experience and health (Leiblum 2000). However, despite the potential of this shift to lead to better understanding of women's sexuality, its concentration within the medical discipline means that research findings should be viewed critically (e.g., Vance 1991), keeping in mind that clinical notions of the role of vaginal lubrication in female sexual function may differ from the experiences and perceptions of individual American women.

\section{Discussion}

This literature review highlights the significant gaps in our knowledge of differing cultural norms, preferences, and practices regarding lubrication during sex, because few studies to date have focused on this topic. Existing research—for instance on vaginal practices — could provide a framework for how some people or communities might interpret or behave with regard to vaginal lubrication; however, the information we have cannot serve as a surrogate for deeper knowledge of actual preferences and practices.

While some researchers have acknowledged the potential impact of lubrication preferences and practices on the acceptability of vaginal microbicides, the majority of studies of the acceptability of microbicides and spermicides have been limited to surveying individuals' opinions on

\footnotetext{
${ }^{8}$ Curiously, the authors write: "It should be noted that, depending upon the definition of the disorder and the type of sample studied, the prevalence of [female sexual arousal disorder] can vary greatly" (p. 76).
} 
narrowly conceived and poorly defined characteristics, such as product volume and degree of messiness, and have thus generated unclear findings. For example, preferences regarding lubrication during sex are frequently solicited by asking participants about their perceptions of the degree of messiness or wetness of a product, or if it provides "excessive" lubrication. Such an approach fails to allow women themselves to define the terms and express their preferences and perceptions regarding lubrication during sex. Furthermore, microbicide trial participants may view their own natural lubrication unfavorably, but the lubrication provided by an artificial product favorably (i.e., that it makes the vagina feel clean and fresh). Participants may attribute such feelings of cleanliness to use of the microbicide product while their perceptions may instead be a result of RTI treatment during the trial. Lastly, preferences expressed in product acceptability studies are limited because of social desirability bias: interviewees often report what they think researchers want to hear and assume that the researchers support the products they are testing. Therefore, it is not yet clear how women and men in different cultures think about lubrication, what amount and types of lubrication individuals would be willing to accept in exchange for a certain level of protection against HIV, and how these findings will affect microbicide acceptability and use, once available.

Other direct and indirect links between vaginal lubrication and vulnerability to HIV may exist. For instance, there is some evidence that lack of lubrication may increase condom breakage, while excessive lubrication may increase condom slippage. Furthermore, acceptability of the female condom may be negatively affected by perceived messiness or excessive lubrication. Vaginal practices may increase vulnerability for HIV by damaging the vaginal walls and disrupting the vaginal flora, and also by interfering with the acceptability and use of barrier methods. If researchers find a direct link between such practices and HIV, it may be necessary to discourage the use of all or certain practices altogether. If, however, researchers find that certain practices interfere with barrier methods, it may be sufficient to discourage women from engaging in these practices immediately prior to, during, or after sex. In either case, the HIV research community should take care not to condemn practices without a thorough evaluation of the reasons for their existence (van de Wijgert et al. 2001, p. 143). In particular, more information is needed about the pressure women may experience from their partners and society to engage in such practices, particularly now that vaginal microbicides may become a reality. Finally, women's perceptions of vaginal discharge influence their health care-seeking behavior for RTIs, which in turn may influence their risk for HIV.

Numerous unanswered questions emerge from this review: What are the cultural norms regarding lubrication during sex in various countries, and what are the sources of such norms? Do normative ideas regarding vaginal lubrication differ among communities within the same country or across countries or cultures? To what extent do individuals and couples engage in practices to alter lubrication during sex? Which practices do they perform, and why? Which ranges of lubrication would women and men be willing to accept if microbicides were available that could offer them certain levels of protection against HIV? In the next part, we present the results from a qualitative study of preferences and practices regarding lubrication during sex that explores these questions. 


\section{PART TWO: THE PERSPECTIVES OF KEY INFORMANTS}

Thirteen key informants in the field of women's sexual and reproductive health were interviewed in a qualitative study of norms and behaviors regarding lubrication during sex. The key informant technique has been delineated in handbooks on research methods (e.g., Trotter and Schensul 1998; Tremblay 1982) and has been employed in health research (e.g., Moon et al. 2002; Jewkes and Wood 1998; Maticka-Tyndale et al. 1997). The key informant technique can be a valuable tool for cross-cultural research as "[most] members of any community or society do not know the full repertory of forms, meanings, and functions of their culture.... Key informants, as a result of their personal skills, or position within a society, are [ideally] able to provide more information and a deeper insight into what is going on around them" (Marshall 1996, p. 92). The limitations of this method, and the particular limitations of the manner in which the technique was employed in this study, are reviewed in a subsequent section. Key informants in this study included public and reproductive health researchers, social scientists, advocates, and medical professionals working in a variety of countries in Africa, Asia, Latin America, and North America. Informants were interviewed for their professional perspectives on the ways in which preferences and practices regarding lubrication during sex in the countries in which they work might affect individuals' and couples' acceptance of vaginal microbicides. Interview data highlight the diverse personal and cultural factors that shape individual preferences and practices regarding lubrication during sex and lead to varying levels of acceptability of vaginal products.

\section{Methods}

Potential key informants were identified through the Population Council's field offices, other reproductive and public health research organizations, and relevant publications. Twenty-two potential informants were initially contacted via e-mail; six refused to participate, three didn't respond, and 13 agreed to participate. ${ }^{9}$ The 13 informants work in the following nine countries: Brazil ( $N=2)$; Burkina Faso and Senegal $(\mathrm{N}=1)$; India $(\mathrm{N}=2)$; Kenya $(\mathrm{N}=1)$; South Africa $(\mathrm{N}=2)$; Thailand $(\mathrm{N}=2)$; the United States $(\mathrm{N}=2)$; and Zimbabwe $(\mathrm{N}=1)$. All informants are highly educated female professionals - including researchers, university professors, a laboratory scientist, an HIV/AIDS counselor, a research nurse, and a sex therapist — who are engaged in research and/or advocacy related to a variety of women's health issues.

The study protocol, including a sample interview guide, and an informed consent form were sent to informants for their review, and phone or in-person interviews were scheduled. Written informed consent was obtained from informants prior to each interview, and verbal consent to record the interview was obtained at the beginning of each session. The majority of the interviews were conducted via telephone and lasted from one to two hours. All interviews were conducted in English by the same female interviewer (Sarah Braunstein). At the end of the interview, informants were asked whether they were aware of research on lubrication during sex in their country and to share relevant research documents or reports.

\footnotetext{
${ }^{9}$ Four individuals refused to participate because they felt they were not knowledgeable enough on the topic to be interviewed, and two individuals refused because of time constraints; non response rate $=41 \%$.
} 
A semi-structured interview guide was developed based on salient topic areas that emerged during a review of the literature related to vaginal lubrication (see Appendix). A series of openended questions covered a range of topics, including informants' awareness and understanding of norms and beliefs regarding lubrication during sex; common vaginal practices to achieve the "right" amount of lubrication during sex; normative patterns of partner communication regarding sex; bodily and sexual hygiene, and the role of vaginal lubrication; women's perceptions and health-seeking behavior related to vaginal discharge; clinical ideologies regarding female sexual function and dysfunction and their relationship to norms and behavior regarding vaginal lubrication; and, most importantly, the implications of norms, practices, and preferences regarding lubrication during sex for HIV/STI prevention campaigns, including the acceptability of vaginal microbicides. In addition to these topics, informants' suggestions regarding the design of a larger study on this topic were solicited, including methodology, structure and content of an interview guide, populations from which to recruit participants, and organizations or individuals for potential collaboration. Informants were asked whether they were aware of similar research conducted in the country in which they work, and to share relevant research documents or reports.

All telephone and in-person interviews were taped, and handwritten notes were taken by the interviewer to supplement the recording. Interview tapes were transcribed verbatim, and transcripts were coded manually. The coding closely followed the interview guide, but emerging themes were also explored. Transcripts from different countries were compared for variation and agreement.

\section{Results}

The key informant interviews provided illustrative and rich information. Clear themes emerged across transcripts, and information provided by informants working in the same country was generally in agreement. Data from different countries and regions showed interesting variation.

Norms regarding vaginal lubrication during sex

A "norm" is defined here as an ideology or code of behavior that is held in common by a group of people who share ethnic, geographic, historical, social, or political origin. Norms influence ideas regarding ways of acting, thinking, or behaving, and can be promoted, contested, and modified through behavior and attitudes. In particular, norms regarding sexuality and sexual meaning are culturally embedded, influential, and dynamic: “. . . sexual cultures are to be regarded as social products, made and re-made in daily life ... and therefore adaptable to changing pressures and circumstances" (UNAIDS 1999).

The majority of informants reported norms regarding vaginal lubrication during sex based, in part, on their understanding of popular or common beliefs. In addition to variation between countries, several informants reported significant variation in norms among groups within countries and at the individual level. 
The majority of informants working in Burkina Faso, India, Kenya, Senegal, South Africa, Thailand, and Zimbabwe described explicit norms and popular beliefs regarding vaginal fluids in general, and about lubrication during sex in particular. The informants from South Africa and Zimbabwe reported that explicit norms regarding the presence and amount of lubrication during sex generally proscribe vaginal lubrication during sex. The informant from Kenya reported that, in contrast to other regions such as south and central Africa, nonlubricated sex is not widely promoted. The informant from Senegal reported that, although norms generally are not explicitly discussed as such, their existence is implied by practices among some ethnic groups. For example, as part of initiation for marriage, women are fed a mixture of porridge and roots to increase their natural lubrication thereby enhancing their husband's sexual pleasure. The informants from Thailand explained that the most well-known cultural norms concern the tightness of a woman's vagina, and that women do not typically alter natural vaginal lubrication for sex. Although clear ideas about the role of vaginal lubrication during sex do exist in India, such as the connection between excessive lubrication and vaginal looseness, the informants reported that taboos regarding discussion or recognition of women's sexuality suppressed public acknowledgement of these norms. The informants from Brazil and the United Sates reported that they were not aware of overt norms regarding lubrication during sex. One informant from the United States said: "No, I don't think there are clearly defined or agreed-upon norms [regarding lubrication during sex] in this country. I don't think there's a whole lot of even awareness [of lubrication], either on the part of the woman or the culture at large." ${ }^{\prime 10}$ However, these informants did report that some women in Brazil and the United States may seek medical or psychological care for discomfort during sex due to vaginal dryness, and so even in the absence of explicit norms, there may be some popular ideas about vaginal lubrication and its function during sex. The responses of informants from non-African countries to the question of whether such norms exist may have been influenced, in part, by a perception that practices regarding lubrication during sex are prevalent only in African countries, owing to the significant attention that dry sex has received in the HIV research and prevention literature.

\section{Sources of variation in lubrication norms}

Informants cited a variety of cultural and social factors to which lubrication norms are linked, including prominent sociocultural ideas about sexuality and the body; women's and men's social roles; socioeconomic organization; generational differences (e.g., between adolescents, women of reproductive age, and menopausal and postmenopausal women); access to education and health information; geographic area within a country; ethnic group; rural versus urban setting; differences between types of relationships (e.g., marital, primary, or casual); practices around marriage; and the influence of traditional and modern ideologies on the social environment. For instance, the informants from India reported that norms regarding lubrication during sex are influenced by cultural and religious views regarding vital bodily fluids; negative health consequences - such as physical and emotional weakness, general anxiety, and loss of sexual ability and desire - are associated with the loss of semen and with vaginal discharge. Ideas about women's bodies, sexuality, and body fluids, such as menstrual blood or vaginal discharge, influence norms regarding lubrication during sex; for example, if women's sexuality is viewed

\footnotetext{
${ }^{10}$ This comment exemplifies the extent to which this topic is unexplored- that even seasoned researchers are limited by their own experience.
} 
negatively, bodily fluids that are associated with sex and sexuality, such as menstrual blood and vaginal fluids, are also likely to be viewed negatively. An informant from Thailand reported that sex during menstruation is socially unacceptable there, in part because menstrual blood is thought to be dirty and harmful to men. Further, norms and beliefs differ between young people in urban and rural settings owing to differences in exposure to information about sex and the body. The informant from Kenya said: "The urban children . . . that category, they tend to learn [about sex and ways of preparing themselves for sex] from each other and from magazines and from school, and it's more of an interactive, peer kind of thing. And of course, the media is very influential. ... [For] rural girls, media influence is almost nil. Most of them tend to learn from older women and from seeing what goes on. . . . I mean, you find a 14-year-old from the urban setting knows much more than a 14-year-old who has always lived in a village all her life." Similarly, education influences beliefs and practices related to lubrication. For instance, the informant from Zimbabwe reported that educated women and men are less likely to view the presence of lubrication during sex negatively and thus practice dry sex. This attitude is due, in large part, to their greater access to information on the potential negative health consequences of removing vaginal secretions prior to sex. Finally, some informants reported differences in beliefs and practices between generations, in part because of physiological differences between older and younger women. The US informants, for example, reported that peri- or postmenopausal women are more likely to use commercial lubricants during sex than are younger women, who less frequently experience (or seek treatment for) vaginal dryness.

\section{Significance and purpose of lubrication during sex}

The understanding that individuals or couples have of the role or meaning of vaginal lubrication during sex - its significance - varies between and within countries and cultures. Opinions also vary regarding the presence of lubrication during sex, or whether and at what point a woman should be lubricated for sex, and the source of lubrication. Informants proposed multiple ideologies regarding the significance of vaginal lubrication during sex. In some countries, vaginal lubrication is perceived to facilitate penetration, to help "make sex work." According to this idea, lubrication is needed to avoid or decrease pain or discomfort during sex. The informants from the United States felt that individuals do not typically think about the presence of vaginal lubrication until a decrease in or lack of lubrication interferes with comfortable or pleasurable sex. The informants from Burkina Faso, Kenya, and Senegal reported that the practices of female and male circumcision are widespread among some ethnic groups in these countries. Because of the removal of the clitoris during female circumcision and the particular way in which men are circumcised, individuals who have been circumcised may prefer or require a certain degree of vaginal lubrication for comfort and enjoyment during sex. The informants from Brazil reported that vaginal lubrication is generally viewed as part of the "normal" physiological sexual response; similarly, the informants from Thailand reported that vaginal lubrication is viewed as a necessary component of comfortable sex.

Informants believe that in some countries lubrication is considered to enhance sexual pleasure for one or both partners. The informants from India reported that a certain amount of lubrication during sex is believed to enhance men's sexual pleasure and, to a lesser extent, improve women's sexual satisfaction. The informant from Senegal reported that prior to marriage women are taught to use herbs and roots to increase vaginal lubrication during sex to ensure their future 
husband's pleasure and satisfaction.

In contrast, informants reported that a significant proportion of women in South Africa and Zimbabwe engage in vaginal practices to dry and tighten their vaginas, as was described in detail in the first part of this report. Informants from India and Thailand reported that "excessive" vaginal wetness may be associated with a "loose" vagina, which reduces men's sexual satisfaction. One of the informants from India described a popular metaphor used by men to explain that a "loose" vagina resembles a large cave in which the penis may get lost and within which sexual pleasure cannot be found.

Informants believed that vaginal lubrication is also a result of a woman's sexual arousal; it is a sign of her "readiness" for sex. This perspective may be interpreted in different ways. The informant from Kenya reported that some men believe that a woman whose vagina is dry prior to or during sex is disinterested in sex, which makes men doubt their ability to arouse the woman. An informant from India reported that some Indian women associate their own vaginal lubrication with sexual arousal and pleasure; participants in a study on communication and sexual decisionmaking conducted by the informant reported that when they experience sexual pleasure there is an "emission of water." The informants from the United States reported that a lack of vaginal lubrication is generally interpreted by women and men as a sign that the woman is not sexually aroused or enjoying sex. On the other hand, men in some cultures interpret the presence of vaginal lubrication at the initiation of sex as a sign of their female partners' recent infidelity or promiscuity. An informant from South Africa explained that sex workers often dry their vaginas prior to sex to remove evidence of recent sex with other clients. Women in the general population in South Africa also experience pressure to remove secretions prior to sex, in part to avoid such accusations.

Vaginal wetness is perceived by some women and men as a sign of lack of cleanliness, or a symptom of infection. Informants explained that this idea is related, in part, to taboos around sexual promiscuity, and to negative ideas regarding women's sexuality in particular. The informants from Brazil reported that women may conflate vaginal lubrication with normal or pathological vaginal discharge, and thus view any lubrication unfavorably given strict cultural norms regarding bodily and genital cleanliness and hygiene. Among some groups, vaginal lubrication is viewed as a side effect of injectable contraceptive method use. The informants from South Africa stated that men view a woman's use of an injectable contraceptive method unfavorably because they fear women who use this method will be "excessively wet" during sex, which will detract from their sexual pleasure. ${ }^{11}$

Lastly, informants were asked to what extent there are established clinical definitions of sexual function and dysfunction in the countries in which they work, and whether they believed vaginal lubrication to be an integral component of the diagnosis of sexual dysfunction. Only the informants from the United States described established clinical definitions of sexual dysfunction, which included inadequate vaginal lubrication. The majority of informants from the other countries reported that, although there is not a clinical definition of sexual dysfunction per

\footnotetext{
${ }^{11}$ To our knowledge, there are two publications that discuss increased vaginal discharge as a side effect of injectable contraceptive use: Smit et al. 2002 and Beksinska and Rees 2001.
} 
$s e$, individual women and men likely have personal beliefs regarding sexual function and dysfunction. An informant from South Africa said: "There's nothing like this female sexual dysfunction. ... [A] woman will say what her husband is complaining about her, but she never says, 'This is how I feel.' They just say, 'My husband says I'm cold. He doesn't find me warm like he usually does."”

\section{Optimal amount of lubrication during sex}

Based on informants' reports, opinions regarding the "optimal" amount of lubrication most likely vary between countries, ranging from concerns in India, Kenya, South Africa, Thailand, and Zimbabwe about excessive lubrication to complaints about inadequate lubrication during sex in Brazil and the United States. However, in general, women are expected to achieve a moderate amount of vaginal lubrication during sex that is neither excessive nor inadequate. For example, the informant from Kenya reported that men require a minimal amount of vaginal lubrication during sex to facilitate penetration, but that too much vaginal lubrication is considered messy and thus undesirable. Similarly, the informants from Thailand reported that because both dry sex and excessive vaginal wetness are viewed unfavorably by men, women are under pressure to achieve an intermediate amount of lubrication that facilitates sex, but is not too plentiful to detract from men's pleasure.

\section{Vaginal and sexual practices related to vaginal lubrication}

In order to achieve or maintain the expected amount of lubrication during sex, women may engage in vaginal practices. Informants were familiar with a wide range of such practices. The majority felt that women's preferences regarding lubrication during sex are less likely to influence the practices in which they and their partners engage, because women often have limited sexual negotiating power and their satisfaction is considered secondary to men's. As has previously been reported, most informants described vaginal practices as "women's issues," as women typically engage in such practices without communicating with their male partners.

The expectation that women be "prepared" for sex assumes different meanings across countries. The informants from India, for example, explained that women are expected to appear as though they have not prepared for sex in any way. One informant said: "So, there are norms [in India] around expressions of sexuality and preparedness for sex . . . in the context where ... women are supposed to be unprepared, and not talk about sex, and not express any sexual desire." Informants from other countries, however, reported that women may be expected to be "ready" for sex at any time, and thus perform certain vaginal practices daily. An informant from South Africa explained daily practices: "Most women will before . . . they go to bed. Even if she's tired, she'll make sure she washes her genitalia, applies powder, and if you should ask her why, it's 'I have to be fresh in case my husband wants sex." 'Lastly, several informants drew a connection between negative cultural beliefs about women's bodies, women's level of comfort with touching their own genitals, and the nature and frequency of vaginal practices. An informant from the United States said: "I don't think women [in the United States] like touching themselves. ... They don't like putting things in their vaginas, they don't like pulling things out

of their vaginas even more than they don't like putting things in, you know . . . because the 
vagina for many women, [especially] young women, is kind of a mystery."12 An informant from Brazil hypothesized that their level of discomfort with touching their genitals may explain Brazilian women's infrequent use of vaginal products, including tampons.

Informants were asked to describe the prevalence and nature of vaginal practices in their countries. The four key practices that emerged were vaginal cleansing or douching, vaginal drying, vaginal tightening, and the use of artificial lubricants during sex. Informants' descriptions of the prevalence and nature of these practices varied significantly, as was expected based on the published literature (see the first part of this report).

Hygiene and cleanliness emerged as the most important reasons for vaginal practices. In South Africa, for example, the use of household products (often containing bleach) to clean the vagina is purportedly common, as such products are believed to kill bodily germs in addition to household germs. A wide variety of other products are used in many southern and central African countries, including plain water, water with regular soap, antiseptic soap, lemon and lime juice, and traditional herbs. In India, women also use a variety of products to clean the vagina, including hot water, soda, lime juice, vinegar, and Dettol ${ }^{\circledR}$ antiseptic soap. An informant from India reported anecdotal evidence that a man will check his partner's vagina for infection or "dirtiness" by squeezing lime juice in it to see if it burns. The informant from Burkina Faso described the ritual in which women eat a porridge and root mixture in preparation for marriage; in addition to increasing the woman's lubrication, the mixture perfumes the vagina. Douching is a common vaginal practice in the United States and is written about widely in the literature. The informants from the United States cited that women like to be clean, and that, in fact, "American women may be overly conscientious [about] cleanliness ... so that they wipe away all kinds of natural odors [that are involved in sexual arousal]." The informant from Kenya related norms regarding cleanliness to sexual pleasure: "If anything, people believe in being clean. ... There is a belief that if you are clean you are more likely to arouse somebody . . . and [vaginal lubrication] is dirty so there is this tendency for people to want to clean it up."

Vaginal drying and tightening are also common practices. Informants generally defined vaginal drying as the removal of vaginal secretions prior to sex, and vaginal tightening as the insertion into the vagina of any substance or material to constrict the vaginal walls and create friction and heat during sex. Some informants thought that women and men understand and experience "dry," "tight," "warm," and "clean" as inseparable sensations or features of the sexual experience. For instance, the informants from South Africa and Zimbabwe reported that women may use one product or substance to achieve all four ends. Many different practices were mentioned in addition to the cleansing practices described earlier, including the vaginal insertion of snuff, onion, garlic, traditional herbs, and pharmaceutical products, and wiping out the vagina with cloth, paper, sanitary pads, or cotton wool. Informants from other countries, including Thailand and the United States, described these sensations as distinct from one another. For instance, an informant from Thailand reported a strong emphasis on the value of a tight or "virginal" vagina such that women engage in tightening practices that do not involve removing vaginal secretions. Informants reported three ways that Thai women tighten their vaginas: using commercial feminine hygiene products; using traditional medicines, such as the "Thai herb"

\footnotetext{
${ }^{12}$ These views are surprising given the widespread use of tampons among women in the United States.
} 
from the rural Northeast; or undergoing reconstructive surgery to tighten the vaginal walls. Practices to tighten the vagina after childbirth in order to restore its shape and enhance the male partner's sexual pleasure are also common in west and southern Africa and Brazil. Finally, US informants commented that American women may, on their own or at the instruction of their physicians, practice Kegel exercises after childbirth to restore and strengthen the pelvic floor and vaginal muscles to improve their own and their partner's sexual satisfaction.

Women's perceptions of vaginal discharge are related to issues of hygiene and cleanliness. Whether and at what point women seek health care for vaginal discharge seems to be determined by their perceptions of the cause and significance of vaginal discharge or fluids, and by their ability to distinguish between vaginal lubrication and discharge, and "abnormal" and "normal" vaginal discharge. Informants from several countries, including South Africa and Thailand, reported that women (or men) may perceive normal vaginal lubrication as abnormal because they incorrectly believe it is a sign of a vaginal or sexually transmitted infection. One informant from South Africa reported: "Women sometimes find it difficult to identify a normal versus an abnormal vaginal discharge . . . and so the need to practice dry sex or to remove 'dirt' is based on the fact that a normal vaginal discharge perhaps is perceived as abnormal." The other informant from South Africa expanded on this: "Once a woman experiences discharge, first of all [she] thinks she's been infected ... irrespective of the amount, the type, whether it's smelling or not, maybe they consider discharge as being unclean. They just want to be dry without any discharge." An informant from Thailand explained that women generally do not seek treatment for vaginal discharge until they are experiencing symptoms such as itching.

Informants were also asked about cultural beliefs related to menstruation and menstrual hygiene. Most informants reported that sex during menses was socially unacceptable or considered "unhygienic" in their countries, and some reported that it was strictly forbidden. The informant from Burkina Faso/Senegal described a social myth that says that if a woman engages in sex during menses, she will lose all of her family members. An informant from Thailand reported a commonly held belief that if a man has sex with a woman who is menstruating, his spiritual power or "magic" will be weakened. Some informants described specific customs during menstruation, such as isolating women from others and from their normal duties and activities. The informant from Kenya explained: "Men believe you are dirty at that time, and for the women, you know it's like a time when you should just keep to yourself, [and] they don't involve themselves in a number of things that go on. You notice that women withdraw a little during that time."

The use of artificial lubricants (e.g., oils, creams, or commercial products like K-Y ${ }^{\circledR}$ Jelly or Vaseline $^{\circledR}$ ) to enhance lubrication during sex is another important vaginal practice in many communities. The most common reasons cited for this practice were to enhance pleasure or to minimize pain during sex. For example, an informant reported four social groups in Thailand who use artificial lubricants: teenagers and adults engaging in anal sex to facilitate penetration; heterosexual men to treat erectile dysfunction; perimenopausal urban women to treat vaginal dryness; and commercial sex workers to prevent or treat vaginal dryness. Although the informants from the United States believed that practices with the explicit aim of altering vaginal lubrication are rare, they reported that some individuals or couples may use artificial lubricants to treat sexual difficulties due to vaginal dryness. Interestingly, the US informants did not report 
the use of lubricants to increase sexual pleasure, which has been reported as another common reason for their use. The informants from India reported that women use coconut oil, creams, or Vaseline to lubricate their vaginas for their male partners' pleasure. Finally, women in Burkina Faso use commercial creams or K-Y Jelly during sex to increase lubrication so that their partners are satisfied and stay in the relationship. The informant explained: "In Burkina Faso, you have a lot of women now who are looking for the cream, like K-Y Jelly. Mouth-to-mouth, women will tell each other, 'You know, I use this thing.' . . I think even for these women, it's still to give pleasure to men. . . . I think for them lubrication is important, even if it's not for themselves."

Finally, informants were asked to describe ways that men prepare themselves for sex. While informants felt that women actively prepare for sex more often than men do, some informants did report practices in which men engage prior to sex. In general, they believed that men's activities mostly pertain to ensuring their own satisfaction during sex, and are rooted in conventional notions of masculine sexual performance. Some men use aphrodisiacs to enhance their sexual experience by promoting stamina and sexual prowess, and, to a lesser extent, to increase the sexual satisfaction of their female partners. For example, in rural areas of Kenya, men consume the kukumanga fruit prior to sex because of a common belief that once a man eats the fruit, he must have sex. Some Kenyan men also use Viagra ${ }^{\circledR}$ recreationally or other drugs and alcohol to enhance libido and sexual performance. In India, the majority of men engage in premarital sex during adolescence with young, unmarried women or with sex workers to fulfill social expectations of sexual knowledge and experience prior to marriage. Indian men may use mustard oil to strengthen their erections and increase their virility. An informant from Thailand reported that men undergo scarification - the cutting of a symbol or shape into the penis - or implant glass beads in the penis to enhance their own and their female partners' sexual pleasure. An informant from South Africa reported that men use a commercially available preparation or herbs from traditional healers to maintain their erections for longer periods of time to increase sexual satisfaction.

\section{Gender norms and couple communication regarding lubrication during sex}

Practices regarding lubrication during sex are likely affected by the extent to which and how members of a couple communicate about sex and their patterns of sexual decisionmaking. Most informants reported that in their countries couples do not openly or easily communicate about sex, even though good communication may promote safer sex behavior and greater sexual satisfaction for both partners. In countries where dry sex is common, women circumvent the need for communication by removing vaginal secretions daily so that they are always ready for sex. They also often report pain and discomfort during sex. In most other countries, a significant proportion of women are unable to communicate their own preferences and needs to their partners, and they experience limited sexual satisfaction as a result. The informant from Burkina Faso said: "I don't even know if tradition [in west Africa] will talk about women's preference, because her preference is determined by what can [give] the man pleasure." 
Informants reported that views on lubrication during sex and practices to alter lubrication tend to vary across marital, primary, and casual relationships. Informants from India, Kenya, and Burkina Faso/Senegal mentioned that conventional attitudes about sexuality and marriage may forge a dichotomy between the "good" wife and the "bad" girlfriend, leading men to behave differently in their sexual relationships with their wives and casual partners. Because wives are often viewed as "less sexual" than girlfriends or casual partners, sex within nonmarital or casual relationships may be more open or adventurous. These informants also reported that traditional sexual and vaginal practices occur more frequently within marital relationships, while sex within casual relationships is more heavily influenced by modern ideas about sexuality. Informants also mentioned that condoms are used less frequently in marital or steady relationships. The informant from Kenya explained the dichotomy: "Because the man is usually afraid, especially when it is a girlfriend ... you know, he can lose her anytime, and in a marriage he's got it, but as a girlfriend, he could lose her any minute to anybody else . . . and they'll do anything, so they really go out of their way to make the girls happy." An informant from India reported that men may engage in sexual practices with casual partners that they do not engage in with their wives, such as oral or anal sex. These practices are influenced not only by men's views regarding the "decency" of their wives versus girlfriends, but by women's adherence to cultural norms regarding how they are supposed to behave as wives or girlfriends. Lastly, the informant from Senegal said: "[Men] would prefer [a wife] who is not too sexually oriented. . . But for the casual [partner], they will appreciate a woman who possesses the act of doing things, but not for their spouse because they will not be sure of [the wife]. Maybe she is doing the same thing[s] with other people. Maybe she is learning this because she is going out." It is therefore plausible that practices regarding lubrication during sex vary, depending on the relationship.

Informants reported that women in countries where norms regarding preparation for sex are well established may face consequences for failing to suitably alter vaginal lubrication prior to sex or to prepare for sex in other ways. An informant from South Africa reported that a sex worker can be rejected by clients or risk not being paid if she fails to remove vaginal secretions before sex, or if clients feel her vagina is not tight enough. Further, she may face violence if clients' expectations are not met. The other informant working in South Africa reported that some men insert a finger into their wives' or partners' vaginas to check for lubrication prior to sex, to see if there is "evidence" that she has had sex with someone else. If the man detects vaginal lubrication during this check, the woman may be battered. The informant from Zimbabwe explained that Zimbabwean women who fail to achieve the "right" amount of lubrication for sex can face divorce or be sent back to their families or village by their husbands for further "education" from female relatives on how to be an appropriately dutiful wife. The informant from Kenya reported that both excessive and lack of lubrication can cause strain on relationships, and, in some cases, women are sent to a psychiatrist for resolution of their problem; the informant stressed that "either way, it can be disastrous."

\section{Vaginal lubrication and acceptability of HIV/STI prevention technologies}

Most informants reported that spermicides are infrequently used in their countries owing to limited availability and accessibility and to low acceptability of the method. Most informants reported that the primary reason for low acceptability and infrequent use of spermicides in many countries is user dissatisfaction with messiness, excessive lubrication, or product leakage. For 
instance, an informant from the United States reported that spermicides are not widely used in large part because of the undesirability of their wetness and stickiness, and because they interfere with oral-genital sex. The informant from Zimbabwe said: "I think [spermicides are not widely used] for the simple reason of excessive lubrication if you use a spermicide." In Brazil, South Africa, and Thailand spermicides have not been heavily advertised or marketed, and many individuals are not familiar with these products. Informants reported that, in general, lubricated condoms are more frequently used than nonlubricated condoms. The acceptability of lubricated condoms does not seem to be affected by the amount of lubrication they provide. Dissatisfaction with the method often is due to men's perceptions that condoms decrease sexual pleasure, may cause a loss of erection, interrupt sex, or introduce distrust into a relationship. The informants from Kenya and Zimbabwe were the only ones who reported that condom use depends on the extent to which they don't "over-lubricate" the vagina during sex.

In general, informants were very supportive of the development of an effective vaginal microbicide despite the fact that a microbicide may lubricate the vagina. They felt that women urgently need technologies they can use to protect themselves from HIV, given pervasive obstacles to consistent male condom use and women's inability to negotiate or make decisions in relationships. They felt that women and men may be willing to accept a certain level of increased lubrication in exchange for protection from HIV. An informant from South Africa said: "There is an expressed general need for a concept like vaginal microbicides for women [and] not only [those] at high risk like [the] sex worker population." An informant from Brazil stressed: "We need to invest in this microbicide because it's very necessary now for our population." She also said that her commitment to the idea of vaginal microbicides compelled her to participate in this study. An informant from Thailand, however, was worried about the potential challenges of introducing a new, female-controlled, reproductive technology: "[Whether microbicides will be acceptable] is a very challenging question. It's very difficult to answer because many reproductive technolog[ies], once they get into a male-dominated society like Thailand, then the males use it or initiate it or control it ... I think you need a lot of feasibility stud[ies], cultural appropriateness [studies], and you need to educate men about the acceptability."

Informants predicted that the acceptability and feasibility of microbicides will vary between and within countries according to geographic area, ethnic group, urban versus rural population, and among people by socioeconomic status, age, education level, and gender. They also predicted that the willingness of individuals or couples to use a microbicide will be based, in part, on their perceived vulnerability to HIV, and that fear of infection could supersede other aspects of acceptability, such as product characteristics or how a method is used. For example, the informant from Kenya said: "You know the ... driving thing that would make them use [a microbicide]? For the fear of HIV." Informants felt that sociocultural norms regarding lubrication during sex and related vaginal practices might have implications for the acceptability of vaginal microbicides, although the influence could be bi-directional. On the one hand, norms that make only a very specific "optimal" amount of lubrication during sex acceptable may negatively affect acceptability. On the other hand, vaginal practices might support acceptability as women who engage in such practices are likely more comfortable with inserting products into the vagina and with touching their genitals in general. As an informant from Thailand said: "I'm sure the women would use [a vaginal microbicide] in Thai culture because women are familiar with vaginal practices, douching, inserting, you know." However, informants believed that in 
cultures or relationships in which there are consequences for women who fail to achieve the "right" amount of lubrication during sex women may be deterred from using a vaginal microbicide that delivers an amount of lubrication unequal to their natural amount. Informants reported that an individual's hygiene practices could also significantly affect acceptability of microbicides. A product that makes women and their partners feel "clean" or "fresh" during sex would likely be highly acceptable if norms promote hygiene and genital cleanliness for sex. Such norms regarding hygiene have implications for product formulation. For instance, several informants expressed the opinion that a product that is clear or light in color, that is in gel or cream form rather than a suppository or foam, and that is odorless and tasteless would likely be perceived as "clean" by users. An informant from Thailand said: "I can say that if you make [the microbicide] nice, not [a] very strong smell and clear-it should be clear first thing. This is not a medical product ... this is not a chemical but something to add to your sexual pleasure and some

prevention." Similarly, an informant from India said: "In terms of putting something inside, there might be associations with applying a medicated ointment and ... there're notions of illness and would it take away from the fun of sex . . . but the idea of the clear gel might be exciting for some because it's like a vaginal lubricant. . . . Safety doesn't really work. You have to link it up with pleasure."

\section{Discussion}

The informants described explicit norms regarding vaginal lubrication during sex in their countries. In general, ideas about what is sexually desirable, meaningful, and appropriate profoundly influence such norms. Despite significant variation in these norms, a common bottom line emerged: in the majority of countries, women are expected to achieve a moderate amount of vaginal lubrication during sex that is neither excessive nor inadequate. Women may try to achieve this by engaging in a wide variety of vaginal and sexual practices. Informants were very supportive of the development of vaginal microbicides despite the fact that in some cultures they may be perceived as over-lubricating the vagina. They agreed that cultural norms and behaviors regarding lubrication during sex will likely affect the acceptability and use of vaginal microbicides when they are first introduced; however, informants working in countries where the HIV epidemic is severe or rapidly emerging felt that women and men may be willing to accept a certain level of increased lubrication in exchange for protection from HIV.

Few informants were aware of research on lubrication during sex in the country in which they work. All informants agreed that a multi-country, multi-site study of individuals' and couples' preferences and practices regarding lubrication during sex, and their potential effect on the acceptability of microbicides, would help to clarify important differences within countries as well as between countries. Such research will increase our understanding of the degree to which product characteristics related to lubrication will influence acceptability and use, and how best to market and promote microbicides once they are available. The relationship between the acceptability of spermicides and male condoms and the potential acceptability of vaginal microbicides is complex. Based on interview data, it is not possible to predict whether there will be a relationship between the acceptability of these three methods. The novelty of microbicides and their female-controlled design will likely distinguish them from existing prevention methods. 
The key informant technique has several important limitations. First, there are inherent disadvantages to using key informants to obtain information on embedded cultural processes. In key informant research, the unit of analysis is an "expert"- a professional in the field or a distinguished community member-rather than an individual or couple who could report on actual behavior. Conventionally, key informants are chosen because they are "individuals in the community who have extensive expertise in an important cultural domain [about which the researcher is concerned]" (Trotter and Schensul 1998, p. 705). The researcher is interested in gathering information on highly standardized knowledge or cultural patterning on a certain topic that is beyond the purview of the average community member. As such, however, using key informants does not allow the researcher to gain an understanding of "the range of variation among individuals with respect to that cultural domain" (p. 704).

The second set of limitations arises from the selection and particular characteristics of key informants in this study. An important criterion for the selection of key informants is that they have direct access to the desired information, and that they have absorbed it meaningfully and are able to communicate it to the researcher (Tremblay 1982). The informants in this study, however, had limited access to information about cultural trends concerning lubrication during sex, because very little is known about the subject. Instead, the reproductive and sexual health researchers who participated had more general knowledge of patterns of sexual behavior in the country in which they work as a result of extensive professional experience. In addition, because the key informants are both members of their own culture and professionals they may be biased. For these reasons, the data presented here are exploratory. The key informant technique is frequently used to refine research design or inform the development of instruments for future studies (Tremblay 1982). As such, these data can inform future research on this topic by suggesting directions for investigating relevant behavior and attitudes among individuals in these countries.

The immediate challenge is, of course, to provide women with an opportunity for empowerment and self-protection by introducing effective microbicides that are both acceptable to and feasible for use by women and men who are vulnerable to HIV/STIs. Given that norms, personal values, and beliefs shift over time and are influenced by cultural trends and social and political events, it is interesting to consider how customs might (or might not) shift to accommodate new technologies such as vaginal microbicides. However, it is difficult to account for a variety of sexual preferences, practices, and personal and social circumstances in the development of a microbicide; ultimately, several different vaginal microbicides in different formulations will likely be needed to provide a full range of options for women and men from diverse settings. In conclusion, more research on lubrication during sex is needed to better understand microbicide acceptability, and to inform future microbicide product development. 


\section{References}

Alliance for Microbicide Development. Microbicide Research and Development-Products Database, ed. Bowcut JC. Silver Spring, Maryland: Alliance for Microbicide Development, 2002. Available at: http://www.microbicide.org/ProductsDatabase.03May02.current.pdf., accessed 28 September 2002.

Anastasiadis AG, Davis AR, Ghafar MA, Burchardt M, Shabsigh R. The epidemiology and definition of female sexual disorders. World Journal of Urology. 2002;20:74-78.

Aral SO, Mosher WD, Cates W Jr. Vaginal douching among women of reproductive age in the United States: 1988. American Journal of Public Health. 1992 Feb;82(2):210-214.

Awusabo-Asare K, Anarfi JK, Agyeman DK. Women's control over their sexuality and the spread of STDs and HIV/AIDS in Ghana. Health Transition Review. 1993;3(suppl):69-84.

Bang R, Bang A. Women's perceptions of white vaginal discharge: Ethnographic data from rural Maharashtra, in Listening to Women Talk About Their Health: Issues and Evidence from India, eds. Gittelsohn J, Bentley ME, Pelto PJ et al. New Delhi: Har-Anand Publications, 1994.

Beksinska ME, Rees HV. Vaginal discharge: A perceived side effect and minor reason for discontinuation in hormonal injectable users in South Africa. African Journal of Reproductive Health. 2001;5(3):84-88.

Beksinska ME, Rees H, Kleinschmidt I, McIntyre J. The practice and prevalence of dry sex among men and women in South Africa: A risk factor for sexually transmitted infections? Sexually Transmitted Infections. 1999 Jun;75(3):178-180.

Bentley ME, Morrow KM, Fullem A et al. Acceptability of a novel vaginal microbicide during a safety trial among low-risk women. Family Planning Perspectives. $2000 \mathrm{Jul} / \mathrm{Aug} ; 32(4): 184-188$.

Berman JR, Adhikari SP, Goldstein I. Anatomy and physiology of female sexual function and dysfunction. European Urology. 2000;38:20-29.

Berman JR, Bassuk J. Physiology and pathophysiology of female sexual function and dysfunction. World Journal of Urology. 2002;20:111-118.

Berman JR, Berman LA, Werbin TJ, Goldstein I. Female sexual dysfunction: Anatomy, physiology, evaluation and treatment options. Current Opinion in Urology 1999;9:563-568.

Berman JR, Goldstein I. Female sexual dysfunction. Urologic Clinics of North America. 2001 May;28(2):405-416.

Bhatti LI, Fikree FF. Health-seeking behavior of Karachi women with reproductive tract infections. Social Science \& Medicine. 2002;54:105-117. 
Braun V, Kitzinger C. The perfectible vagina: Size matters. Culture, Health \& Sexuality. 2001;3(3):263-277.

Bro F. Vaginal discharge in general practice-Women's perceptions, beliefs and behaviour. Scandinavian Journal of Primary Health Care. 1993 Dec;11(4):281-287.

Brown J, Ayowa OB, Brown RC. Dry and tight: Sexual practice and potential AIDS risk in Zaire. Social Science \& Medicine. 1993;37(8):989-994.

Brown RC, Brown JE, Ayowa OB. Vaginal inflammation in Africa. New England Journal of Medicine. 1992 Aug 20;327(8):572.

Brown JE, Brown RC. Traditional intravaginal practices and the heterosexual transmission of disease: A review. Sexually Transmitted Diseases. 2000 Apr;27(4):183-187.

Chacko MR, McGill L, Johnson TC et al. Vaginal douching in teenagers attending a family planning clinic. Journal of Adolescent Health Care. 1989 May;10(3):217-219.

Chaturvedi SK, Chandra PS, Issac MK, Sudarshan CY. Somatization misattributed to nonpathological vaginal discharge. Journal of Psychosomatic Research. 1993;37(6):575-579.

Civic D, Wilson D. Dry sex in Zimbabwe and implications for condom use. Social Science \& Medicine. 1996;42(1):91-98.

Coggins C, Blanchard K, Alvarez F et al. Preliminary safety and acceptability of a carrageenan gel for possible use as a vaginal microbicide. Sexually Transmitted Infections. 2000a Dec;76(6):480-483.

Coggins C, Blanchard K, Friedland B. Men's attitudes towards a potential vaginal microbicide in Zimbabwe, Mexico, and the USA. Reproductive Health Matters. 2000b May;8(15):132-141.

Coggins C, Elias C, Atisook R et al. A study of women's preferences regarding the formulation of over-the-counter vaginal spermicides. AIDS. 1998;12(11):1389-1391.

Cohen CR, Duerr A, Pruithithada N. Bacterial vaginosis and HIV seroprevalence among female commercial sex workers in Chiang Mai, Thailand. AIDS. 1995;9:1093-1097.

Dallabetta GA, Miotti PG et al. Traditional vaginal agents: Use and association with HIV infection in Malawian women. AIDS. 1995;9:293-297.

Darroch JE, Frost JJ. Women's interest in vaginal microbicides. Family Planning Perspectives. 1999 Jan-Feb;31(1):16-23.

Deniaud F, Fampou-Toundji JC. Acceptability of the female condom amongst commercial sex workers in Thailand and Côte d'Ivoire. International Journal of STD \& AIDS. 1999;10:828-830. Elias C, Coggins C. Acceptability research on female-controlled barrier methods to prevent 
heterosexual transmission of HIV: Where have we been? Where are we going? Journal of Women's Health \& Gender-Based Medicine. 2001;10(2):163-173.

Foch BJ, McDaniel ND, Chacko MR. Racial differences in vaginal douching knowledge, attitudes, and practices among sexually active adolescents. Journal of Pediatric and Adolescent Gynecology. 2001;14:29-33.

Fonck K, Kaul R, Keli F et al. Sexually transmitted infections and vaginal douching in a population of female sex workers in Nairobi, Kenya. Sexually Transmitted Infections. 2001;77:271-275.

Foxman B, Aral SO, Holmes KK. Interrelationships among douching practices, risky sexual practices, and history of self-reported sexually transmitted diseases in an urban population. Sexually Transmitted Diseases. 1998;25(2):90-99.

Friedland B, McGrory CE. U.S. women's attitudes toward a potential microbicide. Poster presentation, Fourteenth Meeting of the International Society of Sexually Transmitted Diseases Research (ISSTDR/IUSTI), Berlin, Germany, June 2001.

Funkhouser E, Pulley L, Lueschen G et al. Douching beliefs and practices among black and white women. Journal of Women's Health \& Gender-Based Medicine. 2002;11(1):29-37.

Gabbay M, Gibbs A. Does additional lubrication reduce condom failure? Contraception. 1996 Mar;53(3):155-158.

Gelfand MM. Sexuality among older women. Journal of Women's Health \& Gender-Based Medicine. 2000;9(suppl 1):S15-S20.

Goldstein I. Female sexual arousal disorder: New insights. International Journal of Impotence Research. 2000;12(suppl 4):S152-S157.

Gorbach PM, Khank Hoa DT, Eng E, Tsui A. The meaning of RTI in Vietnam-A qualitative study of illness representation: Collaboration or self-regulation? Health Education \& Behavior. 1997 Dec;24(6):773-785.

Green G, Pool R, Harrison S et al. Female control of sexuality: Illusion or reality? Use of vaginal products in south west Uganda. Social Science \& Medicine. 2001;52:585-598.

Grésenguet G, Kreiss JK, Chapko MK et al. HIV infection and vaginal douching in Central Africa. AIDS. 1997;11:101-106.

Halperin DT. So dry sex practice does not only happen in Africa! Women's Health Project Newsletter. 2000 Feb;33.

Dry sex practices and HIV infection in the Dominican Republic and Haiti. Sexually Transmitted Infections. 1999 Dec;75(6):445-446. 
Hammett TM, Mason TH, Joanis CL et al. Acceptability of formulations and application methods for vaginal microbicides among drug-involved women: Results of product trials in three cities. Sexually Transmitted Diseases. 2000 Feb;27(2):119-126.

Hardy E, de Pádua KS, Jiménez AL, Zaneveld LJD. Women's preferences for vaginal antimicrobial contraceptives, I-IV. Contraception. 1998;58(4):233-255.

Hatzell T, Feldblum PJ. The female condom: Beyond acceptability to public health impact. Sexually Transmitted Diseases. 2001 Nov;28(11):655-657.

Hira SK, Mangrola UG, Mwale C et al. Apparent vertical transmission of human immunodeficiency virus type 1 by breast-feeding in Zambia. Journal of Pediatrics. 1990 Sept;117(3):421-424.

Hira SK, Spruyt AB, Feldblum PJ, Sunkutu MR, Glover LH, Steiner MJ. Spermicide acceptability among patients at a sexually transmitted disease clinic in Zambia. American Journal of Public Health. 1995 Aug;85(8):1098-1103.

Hunter DJ. AIDS in sub-Saharan Africa: The epidemiology of heterosexual transmission and the prospects for prevention. Epidemiology. 1993 Jan;4(1):63-72.

Irwin K, Mibandumba N, Sequeira D. More on vaginal inflammation in Africa [letter]. New England Journal of Medicine. 1993 Mar 25;328(12):888-889.

Jewkes R, Wood K. Competing discourses of vital registration and personhood: Perspectives from rural South Africa. Social Science \& Medicine. April 1998;46(8):1043-1056.

Jivasak-Apimas S, Saba J, Chandeying V, Sakondhavat C, Kiriwat O et al. Acceptability of the female condom among sex workers in Thailand: Results from a prospective study. Sexually Transmitted Diseases. 2001 Nov;28(11):648-654.

Joesoef MR, Sumampouw H, Linnan M et al. Douching and sexually transmitted diseases in pregnant women in Surabaya, Indonesia. American Journal of Obstetrics and Gynecology. 1996;174(1,1):115-119.

Jones H, van de Wijgert J, Sebola M, de Kock A, Braunstein S et al. Intravaginal practices by phase II Carraguard ${ }^{\mathrm{TM}}$ trial participants in South Africa. Poster presentation, XIV International Conference on AIDS, Barcelona, Spain, July 2002.

Karim QA, Karim SS, Soldan K, Zondi M. Reducing the risk of HIV infection among South African sex workers: Socioeconomic and gender barriers. American Journal of Public Health. 1995 Nov;85(11):1521-1525.

Kendrick JS, Atrash HK, Strauss LT et al. Vaginal douching and the risk of ectopic pregnancy among black women. American Journal of Obstetrics and Gynecology. 1997 May;176(5):991997. 
Kilmarx PH, Limpakarnjanarat K, Supawitkul S et al. Mucosal disruption due to use of a widely distributed commercial vaginal product: Potential to facilitate HIV transmission. AIDS. 1998;12:767-773.

Klebanoff SJ, Coombs RW. Viricidal effect of Lactobacillus acidophilus on human immunodeficiency virus type 1: Possible role in heterosexual transmission. Journal of Experimental Medicine. 1991;174:289-292.

Koblin BA, Mayer K, Mwatha A, Brown-Peterside P et al. Douching practices among women at high risk of HIV infection in the US: Implications for microbicide testing and use. Sexually Transmitted Diseases. 2002 Jul;29(7):406-410.

Kun K. Vaginal drying agents and HIV transmission. Family Planning Perspectives. 1998 Jun;24(2):93-94.

Kutteh WH, Chao C-H, Ritter JO, Byrd W. Vaginal lubricants for the infertile couple: Effect on sperm activity. International Journal of Fertility and Menopausal Studies. 1996;41(4):400-404.

Latka M, Joanis C, Glover L. Acceptability of the Reality ${ }^{\circledR}$ female condom and a latex prototype. Journal of Urban Health: Bulletin of the New York Academy of Medicine. 2001 Dec;78(4):614626.

Laumann EO, Paik A, Rosen RC. Sexual dysfunction in the US: Prevalence and predictors. Journal of the American Medical Association. 1999 Feb 10;281(6):537-544.

Leiblum SR. Definition and classification of female sexual disorders. International Journal of Impotence Research. 1998;10(suppl 2):S104-S106.

- Redefining female sexual response. Contemporary Ob/Gyn. 2000 Nov;45:120-126.

Lichtenstein B, Nansel TR. Women's douching practices and related attitudes: Findings from four focus groups. Women \& Health. 2000;31(2/3):117-131.

Mann JM, Nzilambi N, Piot P et al. HIV infection and associated risk factors in female prostitutes in Kinshasa, Zaire. AIDS. 1988;2:249-254.

Mantell JE, Hoffman S, Weiss E et al. The acceptability of the female condom: Perspectives of family planning providers in New York City, South Africa, and Nigeria. Journal of Urban Health. 2001 Dec;78(4):658-668.

Mantell JE, Myer L, Ramjee G et al. Assessing microbicide acceptability: Current strategies and future directions. In press.

Marshall MN. The key informant technique. Family Practice. 1996;13(1):92-97. 
Martin HL, Richardson BA, Nyange PM et al. Vaginal lactobacilli, microbial flora, and risk of human immunodeficiency virus type 1 and sexually transmitted disease acquisition. Journal of Infectious Diseases. 1999;180:1863-1868.

Maticka-Tyndale E, Elkins D, Haswell-Elkins M. Contexts and patterns of men's commerical sexual partnerships in northeastern Thailand: Implications for AIDS prevention. Social Science \& Medicine. January 1997;44(2):199-213.

Mbizvo MT, Mashu A, Chipato T, Makura E, Bopoto R, Fottrell PF. HIV-1 and HIV-2 prevalence and risk factors in pregnant women in Harare, Zimbabwe. Central African Journal of Medicine. 1996;42(1):14-21.

McMaster J, Pitts M, Poyah G. The menopausal experiences of women in a developing country: There is a time for everything: To be a teenager, a mother, and a granny. Women \& Health. 1997;26(4):1-13.

Merchant JS, Oh MK, Klerman LV. Douching: A problem for adolescent girls and young women. Archives of Pediatrics and Adolescent Medicine. 1999 Aug;153(8):834-837.

Moon MW, Khumalo-Sakutukwa GN, Heiman JE et al. Vaginal microbicides for HIV/STI prevention: What key informants say. Journal of Transcultural Nursing. 2002 Jan;13(1):19-22.

Morar NS, Abdool Karim SS. Vaginal insertion and douching practices among sex workers at truck stops in KwaZulu-Natal. South African Medical Journal. 1998 Apr;88(4):470.

Nichter M. Anthropology and International Health: South Asian Case Studies. Dordrecht, Netherlands: Kluwer Academic Publishers, 1989.

Nzila N, Laga M, Thiam MA et al. HIV and other sexually transmitted diseases among female prostitutes in Kinshasa. AIDS. 1991;5:715-721.

Oh MK, Merchant JS, Brown P. Douching behavior in high-risk adolescents: What do they use, when and why do they douche? Journal of Pediatric and Adolescent Gynecology. 2002;15:8388 .

Onderdonk AB, Delaney ML, Hinkson PL, DuBois AM. Quantitative and qualitative effects of douche preparations on vaginal microflora. Obstetrics and Gynecology. 1992 Sept;80(3-1):333338.

Orubuloye IO, Caldwell P, Caldwell JC. A note on suspect practices during the AIDS epidemic: Vaginal drying and scarification in southwest Nigeria. Health Transition Review. 1995;5(suppl):161-165.

O’Toole Erwin J. Reproductive tract infections among women in Ado-Ekiti, Nigeria: Symptoms recognition, perceived causes and treatment choices. Health Transition Review. 1993;3(suppl):135-149. 
Patel V, Oomman N. Mental health matters too: Gynaecological symptoms and depression in South Asia. Reproductive Health Matters. 1999 Nov;7(14):30-38.

Pavlova SI, Tao L. In vitro inhibition of commercial douche products against vaginal microflora. Infectious Diseases in Obstetrics and Gynecology. 2000;8(2):99-104.

Pitts M, Magunje N, McMaster J. Students' knowledge of the use of herbs and other agents as preparation for sexual intercourse. Health Care for Women International. 1994 MarApr;15(2):91-99.

Pool R, Whitworth JA, Green G et al. Ambivalence, sexual pleasure and the acceptability of microbicidal products in south-west Uganda. AIDS. 2000a;14(13):2058-2059.

An acceptability study of female-controlled methods of protection against HIV and STDs in south-western Uganda. International Journal of STD \& AIDS. 2000b Mar;11(3):162167.

Quigley M, Munguti K, Grosskurth $\mathrm{H}$ et al. Sexual behaviour patterns and other risk factors for HIV infection in rural Tanzania: A case-control study. AIDS. 1997;11:237-248.

Rajamanoharan S, Low N, Jones SB, Pozniak AL. Bacterial vaginosis, ethnicity, and the use of genital cleaning agents: A case control study. Sexually Transmitted Diseases. 1999 Aug;26(7):404-409.

Ramjee G, Gouws E, Andrews A, Myer M, Weber AE. The acceptability of a vaginal microbicide among South Africa men. International Family Planning Perspectives. 2001 Dec;27(4):164-170.

Ray S, Bassett M, Maposhere C et al. Acceptability of the female condom in Zimbabwe: Positive but male-centered responses. Reproductive Health Matters. 1995 May;5:68-79.

Ray S, Gumbo N, Mbizvo M. Local voices: What some Harare men say about preparation for sex. Reproductive Health Matters. 1996 May;7:34-45.

Reed BD, Ford K, Wirawan D. The Bali STD/AIDS study: Association between vaginal hygiene practices and STDs among sex workers. Sexually Transmitted Infections. 2001;77:46-52.

Roddy RE, Feldblum PJ. Analytical methodology in a cohort study of cofactors of sexual transmission of human immunodeficiency virus. Journal of Infectious Diseases. 1991;164:12361237.

Rojanapithayakorn W, Goedken J. Lubrication use in condom promotion among commercial sex workers and their clients in Ratchaburi, Thailand. Journal of the Medical Association of

Thailand. 1995 Jul;78(7):350-353. 
Rosenberg MJ, Phillips RS, Holmes MD. Vaginal douching: Who and why? Journal of Reproductive Medicine. 1991 Oct;36(10):753-758.

Runganga AO, Kasule J. The vaginal use of herbs/substances: An HIV transmission facilitatory factor? AIDS Care. 1995;7(5):639-645.

Runganga A, Pitts M, McMaster J. The use of herbal and other agents to enhance sexual experience. Social Science \& Medicine. 1992;35(8):1037-1042.

Sandala L, Lurie P, Sunkutu MR et al. "Dry sex" and HIV infection among women attending a sexually transmitted diseases clinic in Lusaka, Zambia. AIDS. 1995;9(suppl 1):S61-S68.

Séhonou J, Grésenguet G, Tokunaga $M$ et al. Acceptability of the female condom in Bangui, Central African Republic: Results from a prospective study. International Journal of STD \& AIDS. 2002 Sep;13(9):649-651.

Sewankambo N, Gray RH, Wawer MJ et al. HIV-1 infection associated with abnormal vaginal flora morphology and bacterial vaginosis. Lancet. 1997 Aug 23;350(9077):546-550.

Smit J, McFayden L, Zuma K, Preston-Whyte E. Vaginal wetness: An underestimated problem experienced by progestogen injectable contraceptive users in South Africa. Social Science \& Medicine. 2002;55(9):1511-1522.

Smith AMA, Jolley D, Hocking J, Benton K, Gerofi J. Does additional lubrication affect condom slippage and breakage? International Journal of STD \& AIDS. 1998 Jun;9(6):330-335.

Snowden R, Christian B. Patterns and Perceptions of Menstruation. New York: St. Martin's Press, 1983.

Sparrow MJ, Lavill K. Breakage and slippage of condoms in family planning clients. Contraception. 1994 Aug;50:117-129.

Spruyt A, Steiner M, Joanis C et al. Identifying condom users at risk for breakage and slippage: Findings from three international sites. American Journal of Public Health. 1998 Feb;88(2):239244. 
Steiner M, Piedrahita C, Glover L et al. The impact of lubricants on latex condoms during vaginal intercourse. International Journal of STD \& AIDS. 1994 Jan-Feb;5(1):29-36.

Steiner M, Spruyt A, Joanis C et al. Acceptability of spermicidal film and foaming tablets among women in three countries. International Family Planning Perspectives. 1995 Sept;21(3):104107.

Taha ET, Hoover DR, Dallabetta GA et al. Bacterial vaginosis and disturbances of vaginal flora: Association with increased acquisition of HIV. AIDS. 1998;12:1699-1706.

Tremblay M-A. The key informant technique: A non-ethnographic application, in Field Research: A Sourcebook and Field Manual, ed. Burgess RG. London: George Allen \& Unwin, 1982.

Trollope-Kumar K. Cultural and biomedical meanings of the complaint of leukorrhea in South Asian women. Tropical Medicine \& International Health. 2001 Apr;6(4):260-266.

Trotter RT, Schensul JJ. Methods in applied anthropology, in Handbook of Methods in Cultural Anthropology, ed. Bernard HR. Walnut Creek, California: AltaMira Press, 1998.

UNAIDS. Report on the Global HIV/AIDS Epidemic. Geneva, Switzerland: UNAIDS, 2002. Available at: http://www.unaids.org/barcelona/presskit/barcelona\%20report/cover.pdf, accessed 23 January 2003.

- Sex and Youth: Contextual Factors Affecting Risk for HIV/AIDS. A Comparative Analysis of Multi-site Studies in Developing Countries. Geneva, Switzerland: UNAIDS, 1999. Available at: http://www.unaids.org/publications/documents/children/children/ sexandyouth99.html, accessed 3 October 2002.

van de Wijgert JHHM, Chirenje ZM, Iliff V et al. Effect of intravaginal practices on the vaginal and cervical mucosa of Zimbabwean women. Journal of Acquired Immune Deficiency Syndromes. 2000a May 1;24(1):62-67.

van de Wijgert J, Coggins C. Microbicides to prevent heterosexual transmission of HIV: Ten years down the road. AIDScience. 2002;2(1):1-10.

van de Wijgert J, Cornelisse P, Morrison C, Chitsungo S et al. Baseline associations between vaginal practices and vaginal infections in Zimbabwean, Ugandan and Thai women. Poster presentation, XIV International Conference on AIDS. Barcelona, Spain, July 2002.

van de Wijgert JHHM, Khumalo-Sakutukwa GN, Coggins C et al. Men's attitudes toward vaginal microbicides and microbicide trials in Zimbabwe. International Family Planning Perspectives. 1999 Mar;25(1):15-20. 
van de Wijgert J, Mason PR, Gwanzura L et al. Intravaginal practices, vaginal flora disturbances and acquisition of sexually transmitted diseases in Zimbabwean women. Journal of Infectious Diseases. 2000b Feb;181:587-594.

van de Wijgert J, Mbizvo M, Dube S, Mwale M, Nyamapfeni P, Padian N. Intravaginal practices in Zimbabwe: Which women engage in them and why? Culture, Health \& Sexuality. 2001;3(2):133-148.

Vance CS. Anthropology rediscovers sexuality: A theoretical comment. Social Science \& Medicine. 1991;33(8):875-884.

Vermund SH, Sarr M, Murphy D et al. Douching practices among HIV infected and uninfected adolescents in the US. Journal of Adolescent Health. 2001 Sept;29(suppl 3):80-86.

Winkvist A, Akhtar HZ. Images of health and health care options among low-income women in Punjab, Pakistan. Social Science \& Medicine. 1997 Nov;45(10):1483-1491.

Witte SS, El-Bassel N, Wada T, Gray O, Wallace J. Acceptability of female condom use among women exchanging street sex in New York City. International Journal of STD \& AIDS. 1999;10:162-168.

Zhang J, Thomas AG, Leybovich E. Vaginal douching and adverse health effects: A metaanalysis. American Journal of Public Health. 1997;87:1207-1211. 


\section{Appendix: Key Informant Interview Guide}

\section{Introduction}

As you know from our earlier e-mail correspondence, I am in the process designing a qualitative study of women's and men's preferences and practices regarding lubrication during sex in various countries and cultures. I am currently conducting the exploratory phase of this study, a (telephone) inquiry of reproductive and sexual health researchers who I think will be able to provide direction for the design of the main phase of this study. For the main phase, I hope to conduct personal in-depth interviews and focus group discussions with women, men, and couples in several cultures or countries.

I am interested in your professional perspectives on this topic and in hearing about your related research experience. Additionally, it would be very helpful if you could suggest other researchers with whom I might speak in [country], and further, if you could send us any pertinent written research materials or data. I am interested in your point of view, your perception of the types of/frequency of/reasons for sexual practices and ideas around lubrication in [country] based on your professional experience and individual perspective. I would like to know as much as you can tell me. Would you consent to having this interview taped for easier transcription?

\section{Background Information}

Vaginal lubrication and lubrication during sex have been considered in the following contexts: vaginal practices (e.g., drying and tightening); personal hygiene practices (e.g., douching and menstrual hygiene); vaginal discharge as a reproductive health complaint; female sexual dysfunction; and microbicide acceptability. In case you are less familiar with some of these subtopics, I will provide you with some brief background information on each.

Vaginal practices are believed to be widespread, particularly in Africa. The regular vaginal insertion of a wide variety of herbal and non herbal preparations has been reported in 11 countries in sub-Saharan Africa. Reasons for these practices include removing vaginal secretions, contracting and warming the vagina, and providing sexual satisfaction for the husband through "dry sex" in order to maintain his fidelity, which is the most important longterm reason cited. Research or information on personal hygiene practices, including menstrual hygiene practices and the use of genital cleaning agents such as douche, might also be relevant to the topic of lubrication during sex. Douching has been associated with increased risk for sexually transmitted and reproductive tract infections, such as bacterial vaginosis, pelvic inflammatory disease, and increased risk for ectopic pregnancy. Research on cultural practices around menstruation (either in conjunction with sex or for more general personal hygiene) is more limited but is an area of interest to us and of potential relevance to this project. While research on female sexual dysfunction has largely been conducted in the United States, this topic may be relevant to a discussion of vaginal lubrication in different cultures. Formal definitions and classifications of female sexual dysfunction almost always include (or are based on) lack of or marked decrease in vaginal lubrication as women's principal reason for seeking medical treatment or as a sign of disorders associated with female sexual dysfunction, such as vaginismus or dyspareunia. Some of the discussion around female sexual dysfunction also implicates sexual 
changes resulting from menopause and aging, such as decreased libido or decreased vaginal lubrication. Women's perception of the amount and type of their vaginal discharge, when they consider vaginal discharge to be abnormal, and when they seek medical treatment for it are also important considerations. Finally, there is growing interest in exploring women's preferences and practices around lubrication during sex through research on the acceptability of microbicides. For microbicide research and development, researchers have studied the acceptability of existing spermicides in different formulations. One common finding of most studies in a variety of countries has been that the degree of "wetness" or "messiness" of the product is one of the most important determinants of acceptability.

I am interested in knowing the relevance these topic areas have to your work in [country], and/or other countries or cultures in which you have professional experience; your perceptions of individuals' and couples' practices regarding lubrication during sex in [country]; and if you are aware of behaviors and practices that fit under the categories I have just mentioned.

\section{Interview Questions}

I will now ask you specific questions within each of the subtopics to which I have just referred.

Norms and beliefs regarding lubrication during sex

- Are there cultural norms about lubrication during sex?

- If yes, what are they? (e.g., amount or type of lubrication, or timing)

- Do norms differ between population groups or geographic areas within [country]?

- Are there different standards and norms for men and women?

- What influences norms and beliefs around lubrication during sex? (e.g., religion, spiritual or traditional beliefs, family, education)

\section{Practices to achieve the right amount of lubrication}

- Do women prepare themselves for sex? (e.g., through vaginal drying, tightening, or cleansing practices)

- If yes, what are these practices?

- Are there other purposes for these practices in addition to drying/tightening/cleansing? (e.g., pregnancy prevention, prevention or treatment of RTIs or STIs)

- Who teaches girls how to prepare themselves for sex?

- Do men prepare themselves for sex? Who teaches them? Are there similar influences on men's practices as there are on women's practices?

- Are there consequences (e.g., sexual, relationship, or physical) for women if they do not achieve the right amount of lubrication?

- Is it likely that there are consequences for women (such as relationship problems or stigma) who have beliefs, practices, or behaviors regarding lubrication during sex that contradict cultural norms? (e.g., negative reactions or treatment from peers, elders, community) 
Couple communication regarding sex

- Do women and men communicate about their preferences for lubrication during sex?

- Who initiates discussion of sexual matters (if it occurs) within intimate relationships?

- Is this likely to differ across types of relationships (primary, marital, casual)? What about polygamy or variations in marital practices between groups/cultures?

- Who makes decisions about sexual practices within intimate relationships?

- Is this likely to differ across types of relationships (primary, marital, casual)?

Hygiene practices

- Are there cultural beliefs regarding menstruation?

- Do hygiene practices exist regarding menstruation?

- What norms exist regarding sex during menstruation?

- Do women engage in other hygienic practices, such as douching? If yes, for what purposes?

Clinical notions regarding female sexual dysfunction

- Is there a clinical designation of female sexual dysfunction in [country]?

- Do you think there is a lay perception of normal sexual functioning (or dysfunction) for women and men in [country]?

- If so, what do you think might be individuals' markers of women's sexual function or dysfunction?

- Is the presence or amount of vaginal lubrication part of either the clinical definition of female sexual dysfunction (if one exists) or of sociocultural norms around women's sexual function?

Vaginal discharge

- Is abnormal or "excessive" vaginal discharge a reproductive health complaint of women? Is it something for which women commonly seek treatment?

- At what point, and under what circumstances, do women seek treatment? Where or from whom do they typically seek treatment? Do women self-treat?

- What are the clinical beliefs regarding normal (healthy) versus abnormal (sign of illness) vaginal discharge that may influence women's own ideas about it?

Implications for HIV/STI prevention and education campaigns

- Are spermicides available in [country]?

- If so, is there any evidence that the lubricant properties of spermicides are a deterrent to their use?

- Do norms regarding lubrication affect condom acceptability in this culture? What is the prevalence of condom use in [country]? Do condom users use lubricated or nonlubricated condoms? For what reasons?

- Given women's practices regarding lubrication during sex, do you feel that they will actually use a microbicide that, while preventing the transmission of HIV, will also lubricate the vagina?

- Do you feel men would use a microbicide with their partner(s) if one were available?

Design of the main phase

The purpose of this study is to find out if people in various cultures and countries consider lubrication during sex, what they think about it, whether they engage in certain practices to 
achieve "optimal" lubrication during sex, and what those practices are.

- With that understanding, do you have general suggestions for the design of the main phase of this study?

- Given your knowledge of the culture and communities in [country], do you think it would be feasible for us to talk to women and men there about this topic - both individually and in couples?

- Are there population groups or regions (e.g., age groups, ethnic groups, urban or rural regions) in [country] you would suggest working with in the main phase?

- Are there research methods or approaches that you think would yield useful and interesting information on this topic? Which would be most feasible? In-depth interviews, focus group discussions, both?

- Do you think it would be feasible in the main phase to ask questions similar to those I asked you? Are there questions you would add to the interview guide for the main study?

- Do you have specific suggestions of topic areas to explore that I didn't include in this interview guide?

\section{Other}

- If I did additional work on this topic in your country, what other activities regarding microbicide acceptability would you recommend?

- Do you know of specific social science or other research that has been done on lubrication during sex, or on any of the other topics we discussed?

- Do you know of other researchers with whom I could speak on this topic?

- Do you have any written materials on this topic that you could send?

Thank you very much for your participation. I greatly appreciate your help. 


\section{The Robert H. Ebert Program on Critical Issues in Reproductive Health Request for Other Publications in the Ebert Program Series}

Single copies of available materials are free, unless otherwise noted. Documents may also be photocopied upon request. To obtain publications, mark those requested and mail or fax to: Population Council, The Robert H. Ebert Program, attn: Virginia Kallianes, One Dag Hammarskjold Plaza, New York, NY 10017 USA; fax: 212-755-6052; e-mail: vkallianes@popcouncil.org.

Medical Abortion in China: Results of a Fact-Finding Mission, by Rosa Zhou, Batya Elul, and Beverly Winikoff. 2002. 19 pages.

Informed Consent: From Good Intentions to Sound Practices. A Report of a Seminar, by Susan Y. Wood, Barbara A. Friedland, and C. Elizabeth McGrory. 2002. 43 pages.

Rights, Technology, and Services in Reproductive Health: A Report from a Meeting. 2000. 19 pages.

Reproductive Health Indicators: Moving Forward, by Kelly Blanchard, Batya Elul, and Saumya RamaRao. 1999. 26 pages.

Case Finding and Case Management of Chlamydia and Gonorrhea Infections Among Women: What We Do and Do Not Know, by N. Haberland, B. Winikoff, N. Sloan, C. Coggins, and C. Elias. 1999. 82 pages.

A Study of Women's Preferences Regarding the Formulation of Over-the-Counter Vaginal Spermicides, by C. Coggins, C. Elias, R. Atisook, M. Bassett, V. Ettiegne-Traore, P. Ghys, L. Jenkins-Woelk, E. Thongkrajai, and N. VanDevanter. 1998. 12 pages.

Abortion: Expanding Access and Improving Quality, by Karen Stein, Beverly Winikoff, and Virginia Kallianes. Report from a Population Council seminar. 1998. 83 pages.

Women's Experiences of Unwanted Pregnancy and Induced Abortion in Nigeria, by Friday E. Okonofua, Clifford Odimegwu, Bisi Aina, P.H. Daru, and A. Johnson. Research report. 1996. 37 pages.

Reproductive Tract Infection: Lessons Learned from the Field: Where Do We Go from Here? Proceedings from a Population Council seminar. 1996. 76 pages.

What We Do and Do Not Know About the Menstrual Cycle, or Questions Scientists Could Be Asking, by Sioban Harlow. 1995. 51 pages.

Reproductive Health Approach to Family Planning. Presentations from a panel held on Professional Development Day at the USAID Cooperating Agencies Meeting, February 1994, Washington, DC, compiled by the Population Council. 1994. 71 pages.

Partnership for Prevention: A Report of a Meeting Between Women's Health Advocates, Program Planners, and Scientists. Report from a meeting organized by the Population Council, the Pacific Institute for Women's Health, and the International Women's Health Coalition, May 1994, New York and Washington, DC. 52 pages.

Rethinking Postpartum Health Care, by Beverly Winikoff and Martha Brady. Proceedings of a Population Council seminar, December 1992. 1993. 105 pages.

Maternal Risk, by Beverly Winikoff. Paper presented at Berzelius Symposium, Stockholm, Sweden, May 1991. 13 pages. 
Limitations of Maternal Care to Improve Maternal Health, by Beverly Winikoff. Paper presented at Berzelius Symposium, Stockholm, Sweden, May 1991. 11 pages.

Medical Services to Save Mother's Lives: Feasible Approaches to Reducing Maternal Mortality, by Beverly Winikoff, Charles Carignan, Elizabeth Bernardik, and Patricia Semeraro. Originally published as Working Paper no. 4, March 1991. 58 pages.

$\square$ A Reassessment of the Concept of Reproductive Risk in Maternity Care and Family Planning Services. Proceedings of a 1990 Population Council seminar. 1992. 185 pages. (Executive summary and technical summary also available.)

$\square$ Methodological Issues in Abortion Research. Proceedings of a Population Council seminar, 12-13 December 1989. 124 pages. (Summary report also available.)

Mail to: Population Council, The Robert H. Ebert Program, attn: Virginia Kallianes, One Dag Hammarskjold Plaza, New York, NY 10017 USA; or fax to 212-755-6052.

\section{PLEASE PRINT CLEARLY:}

Name:

Affiliation:

Address:

City/state/country:

Telephone/fax/e-mail:

Please send me the complete Ebert publications list 